\title{
Parallel Lines as Tools for Making Turbulence Visible
}

\author{
Introduction to \\ the Theoretical Background
}

Bruno Latour's idea of the circulating reference. Why is it that we try to achieve new insights, new knowledge, new design by way of making artifacts such as sketches, diagrams, and models? This ubiquitous practice may sound quite banal, but there was some agitation among scholars when the French anthropologist Bruno Latour proposed that the more fabricated and mediated inscriptions are, the better natural scientists can comprehend reality and the more objectivity can be accumulated. Latour is an intellectual who belongs to the "practical turn" in science and technology studies, inquiring into the material manifestations of inscriptions, constructions, and representations. In his seminal early 1990s paper, Circulating Reference, Latour minutely retraced the joint effort of a small interdisciplinary team consisting of a botanist, a pedologist, and two geomorphologists in their mission to find out whether the savanna or the forest was gaining in land area in the Amazonian province of Roraima (Boa Vista). In order to illustrate this process for his readers, he created what he calls a "photophilosophical montage." He distinguished single steps in the research, for example:

1. The scientists inspect a suitable site where the savanna meets the forest.

2. They lean over two kinds of maps, pointing at precise locations.

3. In the forest, numbered tin tags placed on trees mark former visits.

4. The cut specimens of plants are collected, numbered, and put in a certain order in shelves.

5. Later they are inspected on a table.

\footnotetext{
A B S T R A C T This article discusses how two physicists-Etienne-Jules Marey and Friedrich Ahlbornvisualized turbulence in air and water around 1900. Their depictions are based upon several creative and conceptual presuppositions that can be revealed by comparing the work of the two, each of whom employed a field of parallel-aligned lines to depict results. Their similar means of visualizing comparable phenomena turn out to function differently, however, depending on the differences in the ways these lines were conceived and made. REPRESENTA Tions 124. Fall 2013 C The Regents of the University of California. ISSN 0734-6018, electronic ISSN 1533-855X, pages 1-42. All rights reserved. Direct requests for permission to photocopy or reproduce article content to the University of California Press at http:// www.ucpressjournals.com/reprintinfo.asp. DOI: 10.1525/rep.2013.124.1.1.
} 
And so on. Latour describes the path from the phenomena of the expedition to the shared scientific publication as a cascade of aligned acts of measuring, collecting, mapping, abstracting, selecting, classifying, and numbering. He is interested in every connection where something is turned into a notation. Although he is scientifically accurate, he remains at a certain distance from the processes, especially with regard to the pictorial elements. We are not told why the vertical section looks this way and not that; if conventions, personal bias, or cultural practices play a role; or to what extent a preliminary sketch was reworked-or how, or why.

In this project Latour is concerned with an old problem in the philosophy of science. Via a chain of reference, of discontinuous and thus "risky" intermediate steps, he wants to replace a dualistic representational model (the "Great Divide"), one that cannot convincingly bridge the distance between a phenomenon and its iconic or textual representation-that is, between world and word. According to Latour, empiricism shows that a reference is established with each work step where small gaps come about while points of contact are ensured. No single artifact, only the chain of reference as a whole, is able to carry the burden of representation. The reference circulates along the chain if each element is available for review. "An essential property of this chain is that it must remain reversible. The succession of stages must be traceable, allowing for travel in both directions." ${ }^{1}$ The symmetry inherent in Latour's reference system is plausible from a retrospective point of view that mainly looks at the actants. Latour himself offers some decisive hints that the situation does not really function as symmetrically as the expression "reversibility" may suggest. He writes: "We see only an unbroken series of well-nested elements, each of which plays the role of sign for the previous one and of thing for the succeeding one." ${ }^{2}$ The elements are treated in retrospect as signs (or form), and in prospect as thing (or matter). This directionality is crucial. When the researcher points in the direction of "thing," and thus tries to think into the future toward what still has to be found, and when s/he tries to act while the next small step is not yet accomplished, the situation proves considerably more complex and opaque. If, according to Latour, the representation lies solely in the chain of reference and not in a single picture-and much speaks for this hypothesis-how can a scientist then decide about the next steps to take? In the end, one has only the ingredients at one's disposal for problem solving, but no recipe for finding one's way through, says the model theoretician Marcel Boumans. ${ }^{3}$ The tinkering is carried out through the inclusion of the most obvious, namely, what one, with great effort and control, has put in front of one's eyes and into one's hands. It is necessary, then, to take a closer look at what is at hand and to investigate how it is available. 


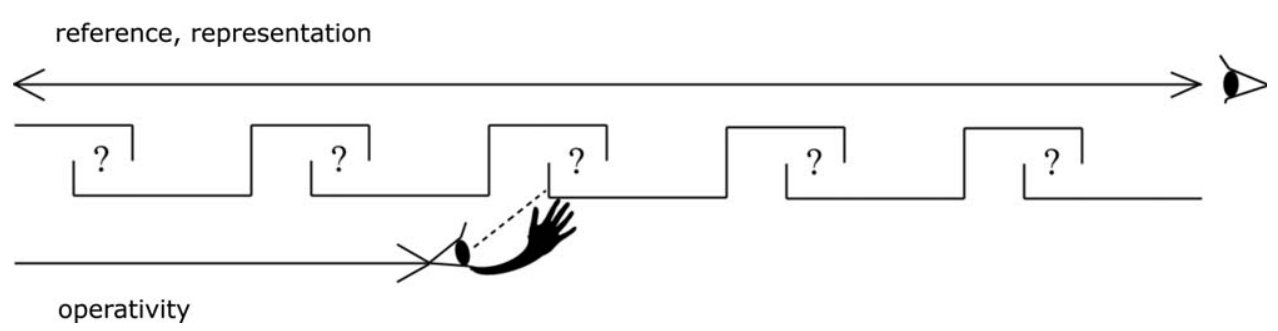

FIGURE 1. Reworking of Bruno Latour's diagram of circulating reference in the sciences (1999). The added hand and eye stand for full-body engagement while operating with the materials at hand. From Bruno Latour,

"Circulating Reference: Sampling the Soil in the Amazon Forest," in Pandora's Hope: Essays on the Reality of Science Studies 73 (Cambridge, MA, 1999), fig. 2.24. With kind permission of Bruno Latour.

On the operativity of images. The idea of operativity is not absent in Latour's thinking, but in my reworking of Latour's diagram of circulating reference (fig. 1), I have added the function of operativity in order to emphasize its importance. The actor-network theory he developed with Michel Callon and John Law indeed offers the idea of spaces of change and translations in which objects of knowledge are handled not only as information in social systems but also as active entities that organize and regulate networks. Thus the agency of nonhuman entities is emphasized. Nonetheless, Latour is much more concerned in his texts with the question of reference, or why scientific outcomes can be so powerful and "universal" though fabricated locally. Latour would probably ask how much operativity (in the sense of ability to connect or to be reworked) is necessary for the representational chain. I would ask how much or which kind of representation is necessary for an image to be operative.

In images and models we find the very particular situation presented and represented at the same time. Both images and models are in a field of tension between representation (depicting something) and productivity (facilitating something). Science historian Evelyn Fox Keller has named the heuristically separate poles within model theory "model-of" and "modelfor." "Operativity" can be linked to the latter.

Models and images can be regarded as instruments or as representations in this context because they are distinguished by the fact that one works with them and on them at the same time. When analyzing how they are used operatively, one pays attention to how they open the scope of activity, provide an opportunity for interaction, support or inhibit certain examinations. ${ }^{5}$ The notion of operativity is rarely used in the context of images, probably because 
they are often not seen as places of actions. The work of philosopher Sybille Krämer is an exception. ${ }^{6}$ She speaks of operativity in the context of diagrams and notational iconicity, meaning manageability and explorability as well as an ability to constitute objects and generate results. For Krämer, diagrams are not only instruments for visualizing but also fields of experiment. This view of operativity may serve to explain how images function in processes of cognition and intervention, how something to be invented can be "found."

\section{The Comparison}

By comparing two case studies in which each experimenter utilized his own complexes of images, building upon his findings and using them as instruments of insight in order to find something new, I hope to provide evidence for the potential of such an approach, one that focuses on production-that is, on how experiments were actually prepared and conducted. I discuss how two experimental scientists-the well-known French physiologist Etienne-Jules Marey and the more obscure German zoologist Friedrich Ahlborn-advanced their efforts to visualize physical turbulences (air and water) at the turn of the twentieth century. How did they engage with their staged model-turbulences? In their aerodynamic and hydrodynamic experiments, they marked the phenomena, created photographic records, and compiled synthesizing diagrams. At first the visualizations they developed may seem quite similar, as they both used fields of parallelaligned lines to represent results. However, any depiction of turbulent flows is based upon several creative as well as conceptual presuppositions. A closer look at how these lines are made and conceived shows that, for various reasons, similar means of visualizing comparable phenomena function differently. By analyzing the visual logic of such a formal arrangement as the field of parallel lines, I ask which of the various but not arbitrary usages were adopted, and to what end. I am keen to extract the differences-which in my argument point to the function of images, their modus operandi-and to get a better understanding of the individual image techniques. I show to what extent the adopted techniques and the purpose-made pictorial artifacts foster or inhibit actions and thus shape the research process. Why, for example, does one of the scientists seem to stall with his line management while the other experiences research-related intellectual flights of fancy?

The protagonists as reflected in the literature. Of the two researchers, Marey is known as the one who systematized and expanded the method of graphical recordings, as one of the pioneers of cinema, and as a forerunner in motion-capture technologies, perfecting the use of the black screen. ${ }^{7} \mathrm{He}$ is 
a widely discussed figure in visual, film, and media studies, as well as in the history of science and history of art. With his dynamographic examinations Marey revolutionized the relation between the traditional visual arts and photography. Together with the photographer Eadweard Muybridge, he "solved" an enigma that puzzled many artists in the nineteenth century, namely, whether a trotting horse at top speed can have, at any given moment, all four hooves off the ground ${ }^{8}$ The associated picture series led to controversial discussions among Muybridge's contemporaries, as the camera view did not correspond to the human impression and contradicted all traditional modes of representation. One faction (Georges Guéroult, Auguste Rodin, and Robert de la Sizeranne) insisted upon the difference between the artistic truth (truth of ensemble) and the scientific truth (truth of detail). The members of the other faction, academic painters like JeanLouis-Ernest Meissonier and Jean-Baptiste-Edouard Détaille, after the initial shock used the instantaneous photographs quite literally to correct the positions of horses' legs in their hippographic artworks. Although Marey himself stated clearly that aesthetics was not his field, together with Georges Demenÿ he conceived an artists' handbook, a chapter of which he titled Locomotion in Man from an Artistic Point of View, which proposed ways artists could use chronophotography (for example, Marey writes that the most visible moments for the eye are the most intense on the photographic plate due to the accumulated exposure times) ${ }^{9}$ Less concerned with positivist questions, the philosopher of aesthetics Paul Souriau appreciated Marey's multiple exposures on a fixed plate not because of any fidelity to nature but because with them a completely new visual language for suggesting the impression of movement could be gained. ${ }^{10}$ Avant garde figures in the arts, such as Georges Seurat, Edgar Degas, František Kupka, and Marcel Duchamp were also attracted by this visual effect. The question of how motion should be represented even led to deep struggles within the Italian futurist group. While Giacomo Balla and the Bragaglia brothers followed Marey in depicting successive phases of a movement, Umberto Boccioni favored the idea of duration and potential force as expressed by the philosopher Henri Bergson-who worked at the same time and institution, covering the same topics as Marey, but holding an opposite view.

According to Marta Braun, who in her seminal book Picturing Time provides an insightful overview of his rich body of work, Marey's images became the "dominant twentieth-century pictorial convention of the dynamic sensation of time." 11 The images seem to correspond to the wish to depict modern experiences of speed and dynamism, and Marey's work in turn became "the key visual source of this aesthetic modernism." ${ }^{12}$ Thus, it is not surprising that many scholars today acknowledge a kind of influence from Marey on younger generations of artists and filmmakers and on some new technological 
inventions. Where such a genealogy is not the primary goal, Marey's work is often discussed within the realm of theory-laden concepts like "memory," "trace," the poetics of the seemingly automatic "self-inscription" of movements, and the "visualization of the invisible." My approach points more to the hands-on side of image- or model-based research-in other words, to the "microbricolage" with artifacts, to use François Dagognet's expression. ${ }^{13}$

Relatively few scholars have dealt with Marey's last experiments, in which he revealed himself as a pioneer of wind tunnels. ${ }^{14}$ The centennial exposition at the Musée d'Orsay, in Paris 2004, entitled Mouvements de l'air was devoted to these experiments. The audience was allowed to play with five very impressive reconstructed wind tunnels. Marey himself hardly published any theoretical commentaries (just four short notes) on his aerodynamic images. ${ }^{15}$ Is this fact a symptom of Marey's being "a polymorphous and bulimic [boulimique] scientist"? 16 This quite dramatic description may suggest simply that Marey did not rest long with one problem and was soon attracted by another topic around his general theme, "movement."

I am more sympathetic to the opinion of theater scholar Daniela Hahn, who says that turbulence also affected Marey's epistemic practice and therefore irritated him. ${ }^{17}$ However, she offers no reason why this might be the case. The science historian Christoph Hoffmann, who compares Marey's work with the streamline experiments of Ludwig and Ernst Mach, shows that quantification became a (largely unsolved) issue in scientific photography around 1900. In his view, these researchers were "to a certain extent 'dazzled' or "trapped' by the capacities of their favorite tools." ${ }^{18}$ I think it is important to open this black box of "tools," or "media," especially as Marey and Ahlborn did not just apply an already fully developed technology to their experiments. The recording devices themselves can be seen as objects of study. Furthermore, I would like to propose an explanation for Marey's lack of success in this case by pointing to the difficulties he encountered in the kinds of images he produced and how he (most likely) engaged with them. His lack of success is closely linked to habits, persistent ways of thinking, established or personal problem-solving strategies, and so on.

But, in general, Georges Didi-Huberman is correct in saying that Marey was gifted in constructing open experimental setups that could surprise him time and again and allowed him to be productive. According to Didi-Huberman, Marey's imaginative genius lay in the fact that "he prolonged these surprises in a heuristic sense and instrumentalized them in a novel way without considering the rule previously axiomatically defined for the experimental apparatus." 19

Although Friedrich Ahlborn was, in my opinion, equally versatile and inventive with respect to his imaging techniques, he has remained largely unknown. Practically no literature exists about him. ${ }^{20}$ While he was certainly a known member of the German-speaking scientific community at the time 
-not least because of his long-running controversy with Ludwig Prandtl, one of the leading flow researchers-he has not left a noticeable trace in the art world. This is no doubt due to the fact that he did not have the means to spread his ideas in richly illustrated volumes. Nonetheless, Ahlborn's images, like Marey's, can be examined in aesthetic terms. He put considerable effort into achieving ideals like clarity by eliminating unwanted artifacts, cropping, accentuating contrasts, symmetrizing, or finding reduced and concise form (ula)s for complexities. This was likely important for convincing himself first of all, and then his colleagues, of the value of his findings, even though it meant accepting a certain tension between singular optical results and reconstructions based on accumulated impressions.

If in the following I address the unquestionably aesthetic images with respect to their purpose, that is, for their epistemic aspect, it is not because I am writing the history of the visualization of turbulence. Likewise, my recovery of Ahlborn is not motivated by ambition to close a gap in the history of experimental physics. Instead, through the following two case studies I want to discuss by example the roles of images in situations of knowledge production. The pioneering attempts of Marey and Ahlborn to deal scientifically with what later would be called chaotic dynamics were carried out in a situation where no secure knowledge and no established procedures yet existed. Another reason their experiments are suitable for my approach is that both developed a three-step procedure for gaining and reworking their images, making it possible to examine what happens with and between each step.

Similarities/Things in Common. What are the commonalities between the two scientists? Both examined birds' flight and moved their research focus from the kinematics of the wing to its effect on the surrounding medium. Thus, initially, both experimented with an air gauge. Soon each dropped this technology because they realized how easily their object of investigation could be influenced. Ahlborn wrote, "The mere measurement is blind. Whoever is able to photograph the current, in addition to the mere measurements, can evaluate his results with much greater accuracy."21 This is why they stopped using measuring apparatuses within the sensitive medium itself. In any case, both of them hoped to get to an understanding of the inner relations and the distribution of forces by making the invisible visible. Both worked as outsiders with only a few collaborators, and each had financial worries. Both were wholehearted experimenters and struggled with the fact that in most cases they were not able to derive a mathematical formulation from their qualitative findings. They felt compelled to put existing flow theories on a reliable foundation through explicit experiments with ideal frictionless liquids. ${ }^{22}$ Around 1900, both turned to the topic of aerodynamics and designed individual experimental setups that permitted 
optical access to the study of turbulence. Both let the findings from their pictorial results leave their mark when it came to making adaptations to the experiments. In their visualization methods, they relied on a shared source of inspiration, the pioneer Ludwig Mach. ${ }^{23}$ Marey became known through chronophotography; Ahlborn occasionally called his pictures "photochronographies." These expressions meant something different in each case, but for both photography was combined with temporality. Astonishingly, Marey also called the photographs of his wind tunnel "chronophotography." If "chronophotography" is defined as a repeatedly exposed

photographic plate, I hope to show why the wind-tunnel photos are not chronophotographs. ${ }^{24}$

In the experiments with flow, both investigators used the visual marking of the phenomenon, which then appeared as a streak formation in the photographs. These streaks came about differently (I will come back to this issue later). In each case, the photographs served as the starting basis for their respective analyses, which were then interpreted in hand-drawn schematic diagrams. Thus both scientists had developed a three-step procedure: first both established differentiations by marking the phenomenon; second, the photographic record was analyzed; and third, the photographic record was synthesized graphically. The following comparison considers the passages between the three steps of the procedures and focuses on a special formal depiction of phenomena used by both: namely, a field of parallelaligned lines. This field of lines turns out to be a productive instance of representation that allowed both scientists to bring clarity into the nonlinear dynamic in the first place. It influenced the research process by opening and facilitating some paths of inquiry and by resisting variation in other respects. To what extent these lines can be further developed or applied in multiple ways also depends how they are made and conceived. And here the differences begin.

\section{Case Study I: \\ Etienne-Jules Marey's Wind Tunnels}

Between the years 1899 and 1901, Etienne-Jules Marey constructed four so-called two-dimensional wind tunnels. In his book Le vol des oiseaux (1890) he had already explained, regarding air resistance, that it is irrelevant whether it is the object or the air that moves, as long as one or the other is at rest. ${ }^{25}$ In his wind tunnels he chose a resting obstacle-which is consistent with his previous work in which it was always dynamic bodies that were examined, in that he now directed his attention to the moving air. Marey's wind tunnels consist of a vitrine into which smoke is piped from 
above through equidistant nozzles. In later versions the smoke filaments are suctioned out from below. The first challenge of this experimental setting was the production of a regular air current. In order to eliminate unwanted eddies (remous) when introducing the smoke, Marey invented a kind of filter system with fine silk gauze stretched over a wooden frame. "In order to prevent the fan attached to the container below and suctioning down the smoke filaments from likewise turning into a 'cause de troubles,' silk gauzes were also arranged on the bottom to regulate the airstream." ${ }^{26}$ In this way, subtle smoke streaks develop-arranged like the strings of a lyre, wrote Marey. ${ }^{27}$ In the approximate middle of the vitrine an object was introduced so that the-here now desired-vortices (tourbillons) of moved air could unfold. Thanks to the experiments he conducted in an aquarium in 1893, Marey was confident that chronophotography could serve for the study of air movement as well as it had for the study of water, and it would show how the air threads behave when meeting obstacles. ${ }^{28}$ Consciously he chose the "distanced medium" of photography in order not to compromise the easily perturbable air. But Marey struggled, as did Ahlborn, with the shock waves and the dust formation caused by the photographic flash. ${ }^{29}$ The flash "surprises" the curling streaks, but on the other hand a permanent illumination heats the air. ${ }^{30}$ The issue of lighting seems to play a central role in turbulence research in general. ${ }^{31}$ The difficulty with light was probably not the sole reason that Marey made only snapshots of his wind-tunnel experiments, and not photographic series, multiple exposures, or films, as he had done in his research into reproducing movement.

A photographic test image (fig. 2) has been preserved that shows Marey's fourth and last wind tunnel without an obstacle. With this he demonstrated that the undisturbed course of the smoke fills the whole chamber with a regularly striated field. This kind of visual calibration is repeated in each of the recordings in the upper third of the image as a sort of inlet flow. In order to gain something scientifically usable, differences must first be established. In working with a camera, an optical contrast is necessary. The difference between a pointed absence of turbulence in the region ahead of the obstacle, on the one hand, and the event, which then can obtrude distinctly and in full clarity, on the other, serves to demonstrate the reliability of the setup.

Excursus: Ahlborn's doubts. In Ahlborn's view, too, the parallelism of lines indicates "calm," and the deviation from it, "event" (fig. 3): "If one were to take a picture without disturbing the water with an immersed body of resistance, these lines would necessarily run parallel and all theoretically have the same length; thus, they would evoke the impression of a uniformly flowing liquid." 32 What works in Ahlborn's water tunnel because of the resting fluid (I will introduce his experimental setup later) is not readily 
FIGURE 2. Etienne-Jules Marey, photograph of wind tunnel with

57 injectors, without obstacle, 1901. From Georges Didi-

Huberman and Laurent Mannoni, Mouvements de l'air, Etienne-Jules Marey, photographe des fluides, (Paris, 2004), plate xii.

Collection Cinémathèque française, Paris.

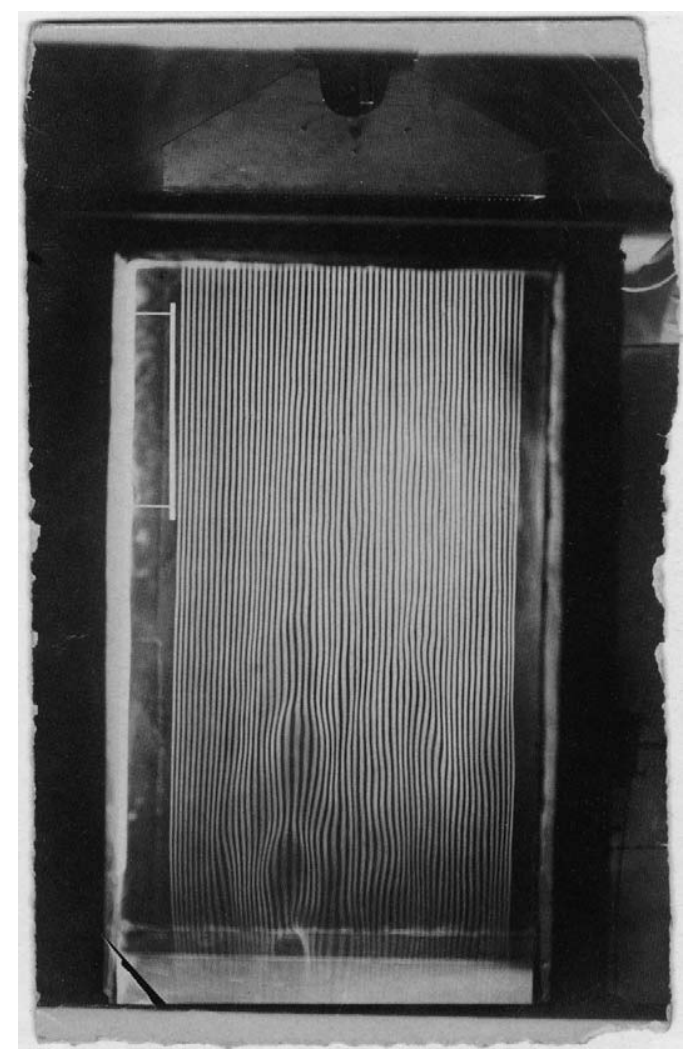

transferable to a wind tunnel where air is introduced. He is convinced that here this calmness is deceptive. Ahlborn indeed appreciated Marey's advances. In Ahlborn's view, however, his colleague (and other contemporaries) had not yet accurately registered the phenomena because their recordings lacked the needed clarity at the crucial location: "Unfortunately, the perturbances next to the introduced bodies are so vast that the fine smoke filaments often lose their contours as they approach the obstacle. And thus, the most essential part of the appearances remain hidden in a uniform mist. Furthermore, the method has the disadvantage that the velocity of the flow cannot be varied much. Further consequences have not been drawn from these images," at least no correct ones, said Ahlborn. ${ }^{33}$ This is not necessarily due to the incompetence of the researchers, "in fact, the immediate observation of this form of air movement [turbulence] is impossible, not only because air is invisible-this problem could in a pinch be remedied by introducing floating visible bodies [Sichtkoerper]-but also because it is a matter of highly involuted, spinning, and at the same time 


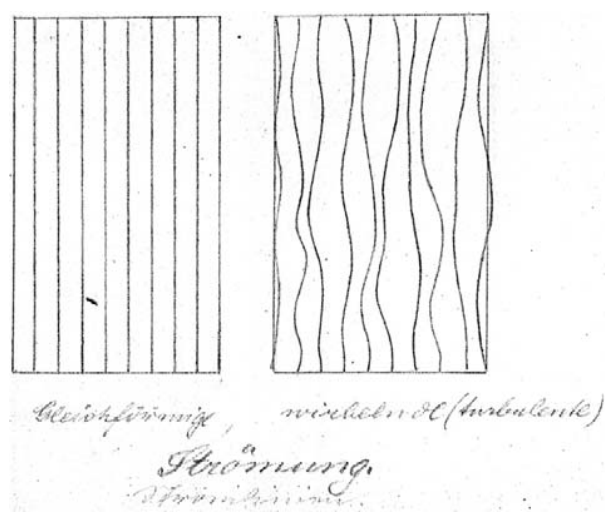

FIGURE 3. Friedrich Ahlborn, sketch showing stream lines in even (left) and whirling or turbulent (right) flow. Deutsches Museum Archiv, Bildstelle, Munich.

progressing movement." ${ }^{34}$ According to Ahlborn, air is not suitable for investigations because it cannot be controlled to a sufficient degree. Indeed, in the wind tunnels one tries to master the situation by switching in so-called flow straighteners. These are wide-meshed alveolar grids made from metal sheets, which are often arranged consecutively in a row. In this way the airflow caused by a turbine is brought into regulated pathways. The photographs of figure 4 depict a wind tunnel without a test object. They show the consequences of staggered, built-in antiturbulence grids on air flow of a constant velocity (12.2 meters per second). Obviously, these devices (as well as Marey's nozzles) achieve the desired effect by divesting the wind of most of its lateral movement.

Nonetheless, Ahlborn expresses his reservations: "The flow straightener however is not only a destroyer but also a generator of turbulent movement because due to friction new eddies must develop along its planes/surfaces" (see fig. 5). ${ }^{35}$ And elsewhere he writes, "The wind jet obtains, through the double layers of opposing, rotating vortices, the same cellular arrangement as the flow straightener and the rotating columns of liquid of the vortices, which envelop each cell space in dense succession, forming a sort of skeleton in the flow that opposes a certain resistance against the deformation through outer forces." 36 The artificial double-rowed Kármán "vortex streets" (a repeating pattern of swirling vortices) disadvantageously affect the research results. For Ahlborn, this is reason enough to study the aerodynamics via the hydrodynamics.

The graphical and chronophotographical methods as precursor techniques. Let me now return to Marey and his smoke filaments, which, at least macroscopically, run in linear paths. Although attractive, pleasing photographic representations of them were not his aim. In order to better anticipate Marey's next steps in light of the test arrangement of his wind tunnels it 


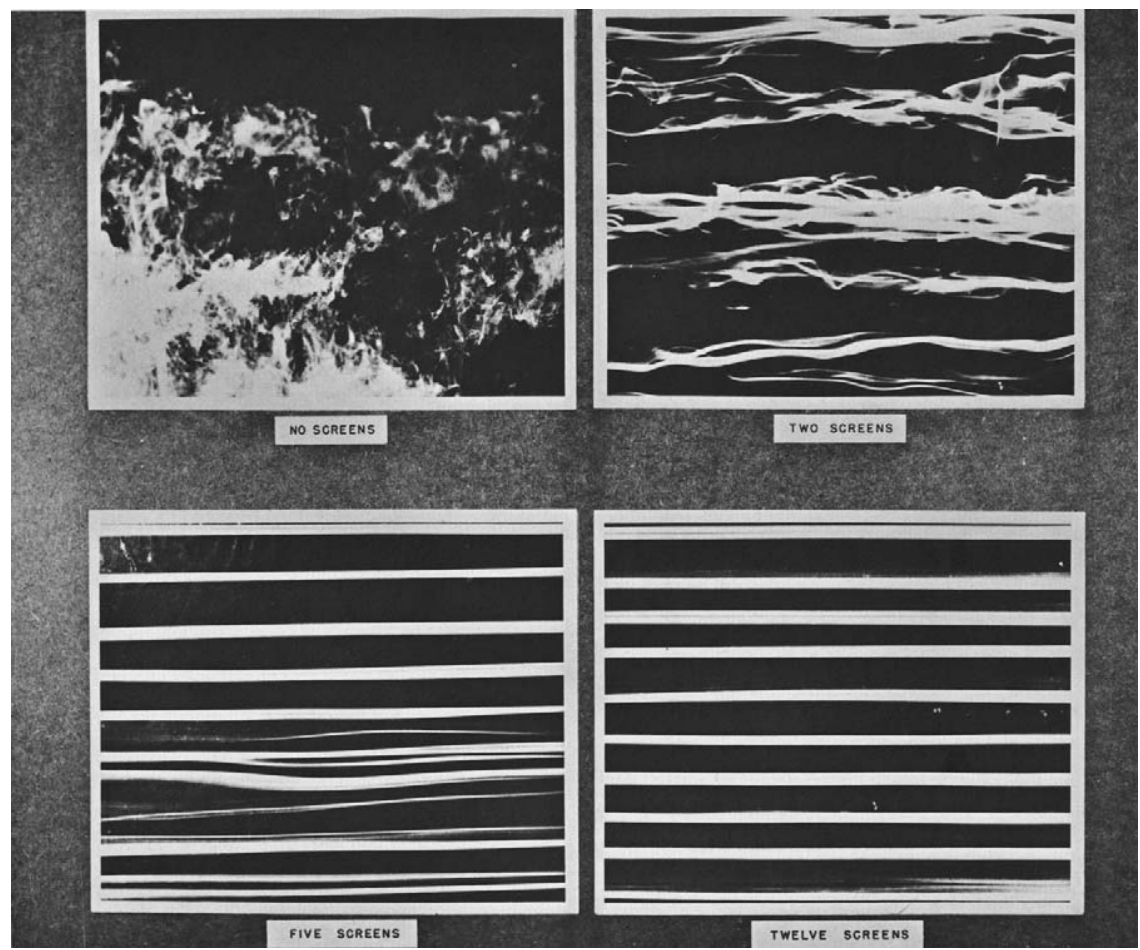

FIGURE 4. F. N. M. Brown, plate with results of different alignments (0-, 2-, 5-, and 12-grid screens) in wind channel, without obstacle, 1971. From F. N. M. Brown, See the Wind Blow (South Bend, IN, 1971).

is necessary to understand the methods he had developed and practiced up to that time.

It has become standard in Marey scholarship to divide his work into two or three distinct stages. Dagognet, for example, speaks of "three Mareys": one studying internal organic movement with the graphic method (until 1870), the second examining external locomotion with chronophotography (until 1890), and the third dealing primarily with physical "subjects"beyond solid bodies (until the end of his life). ${ }^{37}$ John Douard objects that these distinctions could be somewhat misleading because "Marey maintained throughout his career a constant set of theoretical background beliefs, a commitment to attenuated and accessible visual display (the graphical method), and an experimental heuristic of simple decomposition." 38 I also think it is crucial to take into consideration the fact that he carried the results and techniques of all his research into each new problem.

Marey is generally associated with the "graphical method." Though he is considered the method's eponym, a status further consolidated with his 


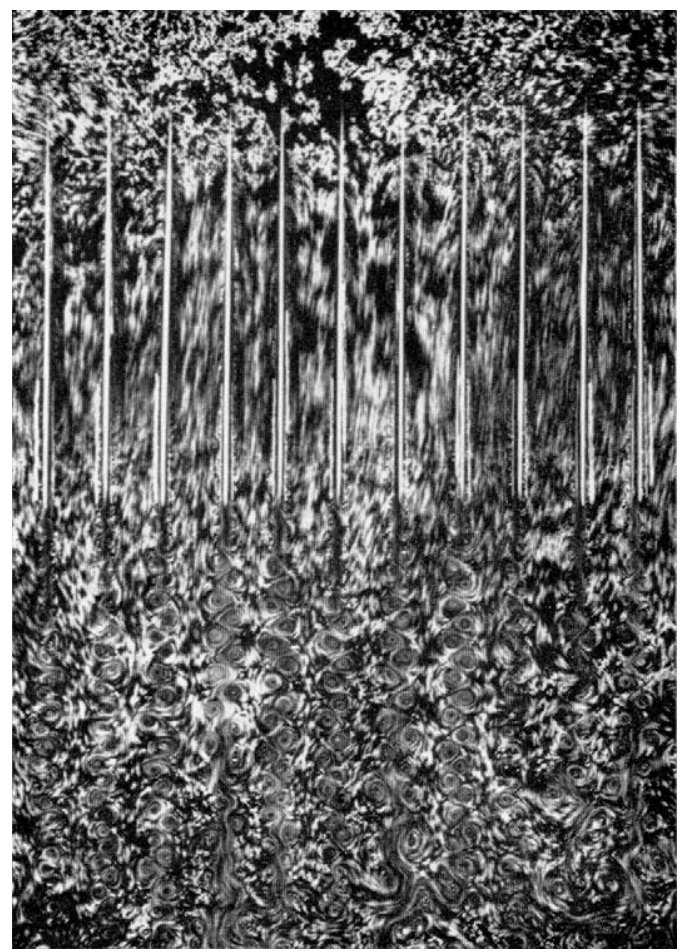

FIGURE 5. Friedrich Ahlborn, "vortex streets" behind a grid (flow straightener), 1931. The plate's length is $10 \mathrm{~cm}$; the distance between the trails is 2 $\mathrm{cm}$. The white lines are due to a light reflection accompanying the rear end of the single elements of the flow straightener. From Friedrich Ahlborn, "Über theoretische und natürliche Strömungen," Flugwesen 10, no. 1 (1930): 5, fig. 8.

book La méthode graphique dans les sciences expérimentales (1878), he is not its inventor. The "graphical method" can be traced back to the beginning of the seventeenth century. ${ }^{39}$ In order to obviate or lessen the need for conventional vivisection, Marey designed noninvasive "sensitive automata," which ideally could gather "autographic" traces from an intact body. Bodily processes like the pulsating expansion of arteries or the movement of the chest while breathing were transmitted mechanically to a quill. The course of the recorded dynamic appeared as a continuous white thread on a constantly rotating, carbon-black cylinder. The recorded horizontal lines simply meant the passing of time; a deviation, however, marked an event, as, for example, the muscle-jerk of a frog's shank provoked by an electric shock (fig. 6).

Marey synchronized different simultaneous recordings of an occurrence on various cylinders by assembling them in a single diagram so that correlations could be more easily discerned. But in the wind tunnel, Marey did not conduct direct measurements. Therefore it is useful to recall a second component that he utilized in his aerodynamic studies: the photographic recording technique. Marey regarded it merely as a special case of the graphical method, to the extent that "it allowed for the 'inscription de mouvements extrèmement rapides' as well as for registering movements 
FIGURE 6. Etienne-Jules Marey, sketch of the functioning of a myograph, 1878.

From Etienne-Jules Marey, La méthode graphique dans les sciences expérimentales et principalement en physiologie et en médecine

(Paris, 1878), 194, fig. 97. Courtesy of

Editions Elsevier Masson SAS.

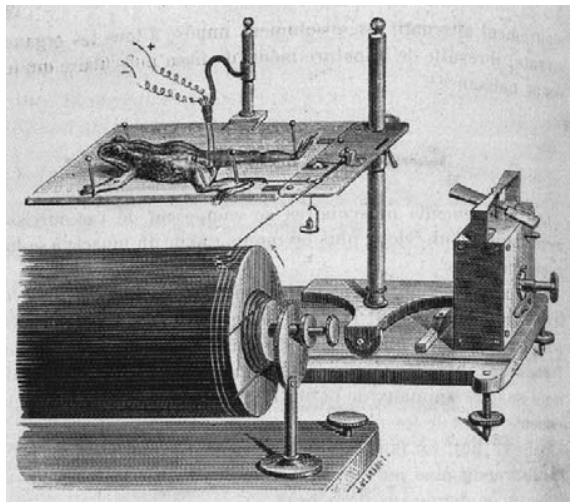

that do not have enough motor power to guide a quill over the paper." 40 The graphical method also has the disadvantage of slightly distorting the recorded curves due to the friction and inertia of the links in the machine's chain. Marey found a solution for this problem with the help of a system that has no inertia: the light beam. ${ }^{41}$ With fixed-plate chronophotography he had several possibilities for capturing a movement. These possibilities indicate that the trade-off for visibility is avoidance of the movement constituted by duration and the introduction of the idea of time into the image. ${ }^{42}$

If he wanted to keep the spatial features and respect the bodily appearance, he got continuous blurring. If he wanted to refine the analysis through the augmentation of the exposure frequencies, he got multiple overlappings of distinct positions. In order to differentiate the positions, he had to reduce the body to reference points. ${ }^{43}$ With the reference points, however, he again caused a kind of uncertainty in need of further interpretation. From another perspective, one could say that the multiple exposure method adds the idea of something continuous to the snapshot, while it is not until the curve that is derived thereby appears that discontinuous measurement points, placed sequentially side by side, are connected. ${ }^{44}$ From the chronophotographs of locomotion, Marey extracts graphics that point more to the movement than to the moved body.

The transcription of the visual traces of chronophotography try to retain two opposed, but for Marey equally important, aspects: the "graphical method" sets the bodies' outer appearance aside in favor of a continuous recording of the movement, while the "photographical method" renounces a continuous recording in order to show the body in movement in a discontinuous view.

Transfer of the graphical and the chronophotographical methods into the wind tunnel experiments. For the wind-tunnel images Marey used the continuous 
line from the graphical method and the multidimensionality from the chronophotographical method (fig. 7). By "multidimensionality" I mean the consideration of synchronous data from several spatially distributed "measurement points." This is why there is not just one smoke filament, but several (and with each new wind tunnel Marey increased them in number). I am convinced that Marey intended to benefit from the same transfer of diagrammatic transcriptions that he had found advantageous with chronophotography.

For this he prepared the object of study in a comparable manner: the movement-carrying elements are successively spread over the whole area of the wind tunnel; they are optically amplified; and the rest of the tunnel is darkened, eliminating spatial depth, limiting the scope of what can happen in the experimental setup, and integrating the measure reference. Moreover, if the analytical evaluation always happens by means of the ex post facto reconstructed trajectories, here, with the smoke filaments, Marey seems to have succeeded in regaining something from the apparent automatism of the graphical recording. The uninterrupted lines are already there as a motif. With this solution, is Marey nearer to his aim of analytic synthesis? Obviously not. Snapshots like the ones we know from his archive still do not allow the researcher to fix the geometry of the temporal process on paper. Instead, perplexity holds sway. Marey confessed to Samuel Langley, who organized a grant to help Marey develop his last wind tunnel, that he was sometimes quite stuck when it came to interpreting certain experimental results. This holds, for example, also for the bizarre paths of smoke threads. ${ }^{45}$ Marey felt himself compelled to the unusual step of begging his colleagues for advice: "I would like to attract the attention of my colleagues, especially of those who study the questions of mechanics, and to ask them to investigate the best conditions for obtaining reliable images of how the air behaves when it comes into contact with solid bodies of various forms. Furthermore, I ask them to enlighten me with respect to the mechanical interpretation of the figures that represent nothing other than the kinematic facts of the problem I am trying to solve." ${ }^{46}$

The field in movement: difficulties and approaches to solving the problem. In the following I would like to briefly sketch why the functional logic of the graphical as well as the chronophotographical method each fall short for the wind-tunnel experiments.

(a) The logic of the graph. Marey mentions musical notation as a role model for the development of graphical writing in physiology. ${ }^{47}$ It is interesting that he established this genealogical connection because, besides the universal claim accompanying it, he revealed something about his conception of the logic of graphical recording. The notation lays down a sequence 
along parallel horizontal lines (which as pentagrams, however, form rigid references for the tone pitch). With respect to movement, the graph functions analogously so that one could say that the present event is exactly where the quill touches the spool. The more we move away from the position of the quill and look at the marks left behind, the more we look back into the past onto former occurrences (or sounds). If we isolate a smoke filament and compare it with a graph, we come to an essential difference and thus to a problem. While the graph fixes (saves), the streak in the wind tunnel remains in motion everywhere, so there is no saved space for the past. Where would the equivalent of the events at the cutting edge of the present be; where is the newest mark showing what is happening right now, if the part of each smoke filament that has proceeded the farthest forward is the oldest? Here, the vanguard has accumulated the most "history." On one hand, the foremost part is the oldest, and if it reaches the lower end of the tunnel, it disappears. On the other hand, nothing revealing has happened yet where the smoke streaks freshly enter the scene in the upper part of the wind tunnel. From these admittedly strange considerations it turns out that the graphical logic of recording does not work here. In any case, the fixation of events happens differently with the photographic apparatus.

(b) The logic of chronophotography. In his presentation for the World's Fair of 1900 (fig. 8), Marey arranged the wind-tunnel images transversely, so that the striations lay horizontally. In this way the same horizontal reading direction as that in the chronophotographical studies is suggested. At first sight, the difference seems solely to reside in the fact that in the wind tunnel the movement is not carried out by a clearly defined body at a specific place. However, this homology probably arises more from a wish than from a similar manageability of the outcome. The main difference lies in the fact that here the whole field is always filled with movement. For chronophotography, too, Marey could only use the change at the outer edge, because the rest of the image surface is reserved for archiving past stages. ${ }^{48}$ When taking a snapshot, the constant smoke supply does not disturb the region ahead of the obstacle because the distinction is preserved. As soon as a multiple exposure is envisaged, the constant supply certainly causes multiple superpositions, and nothing is gained. After the obstacle, there is the additional, greater difficulty that this visualizing technique loses its marking character by diffusing. For the chronophotographical record one needs an area as limited as possible, in which the most significant events occur followed by darkness so that what is registered does not fade. The narrower this area is, the less confusion the events on the photographic plate cause. Hence, an upright walking human being is better suited than a horse to this technique, and the technique itself proves to be motif dependent. 


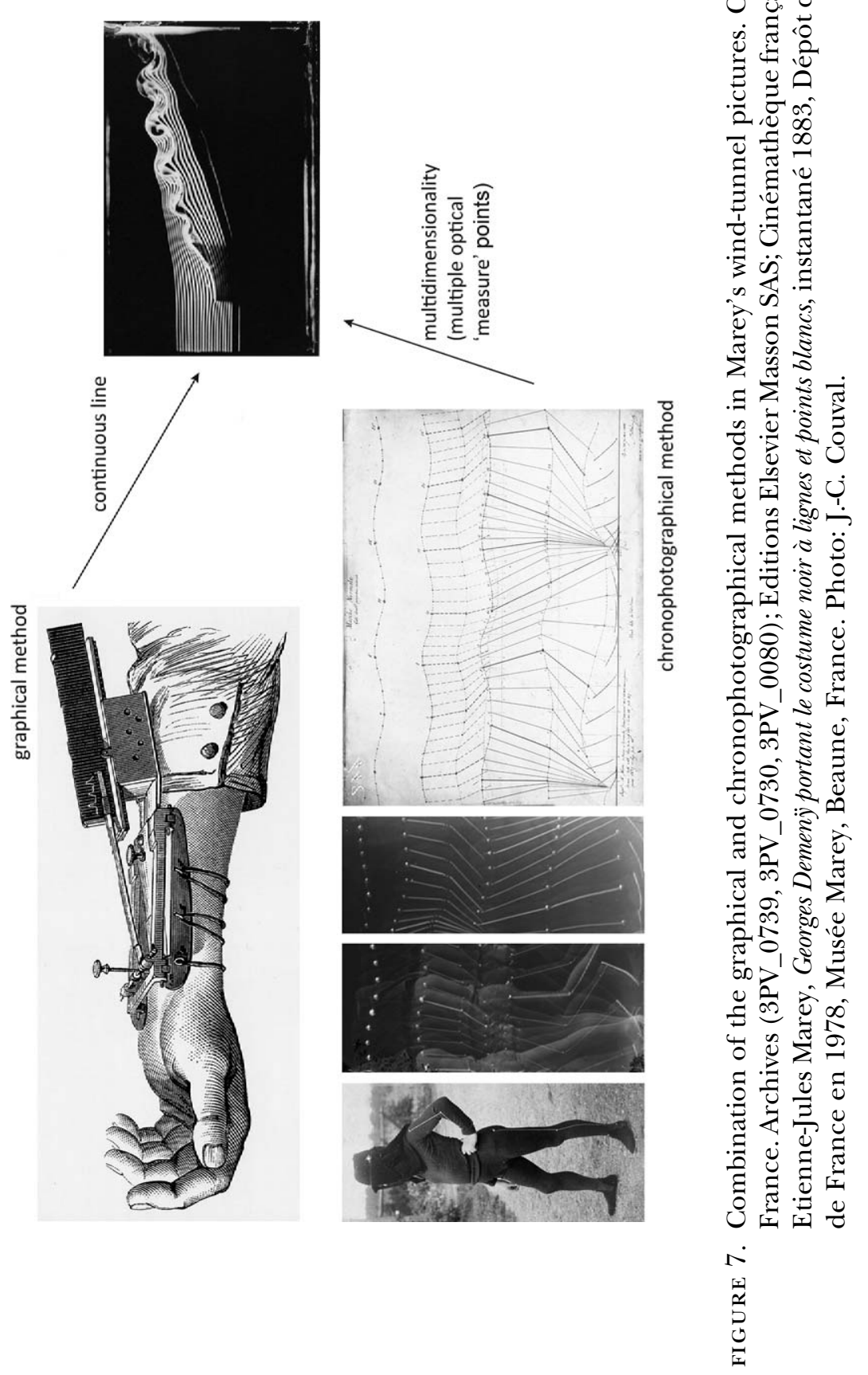




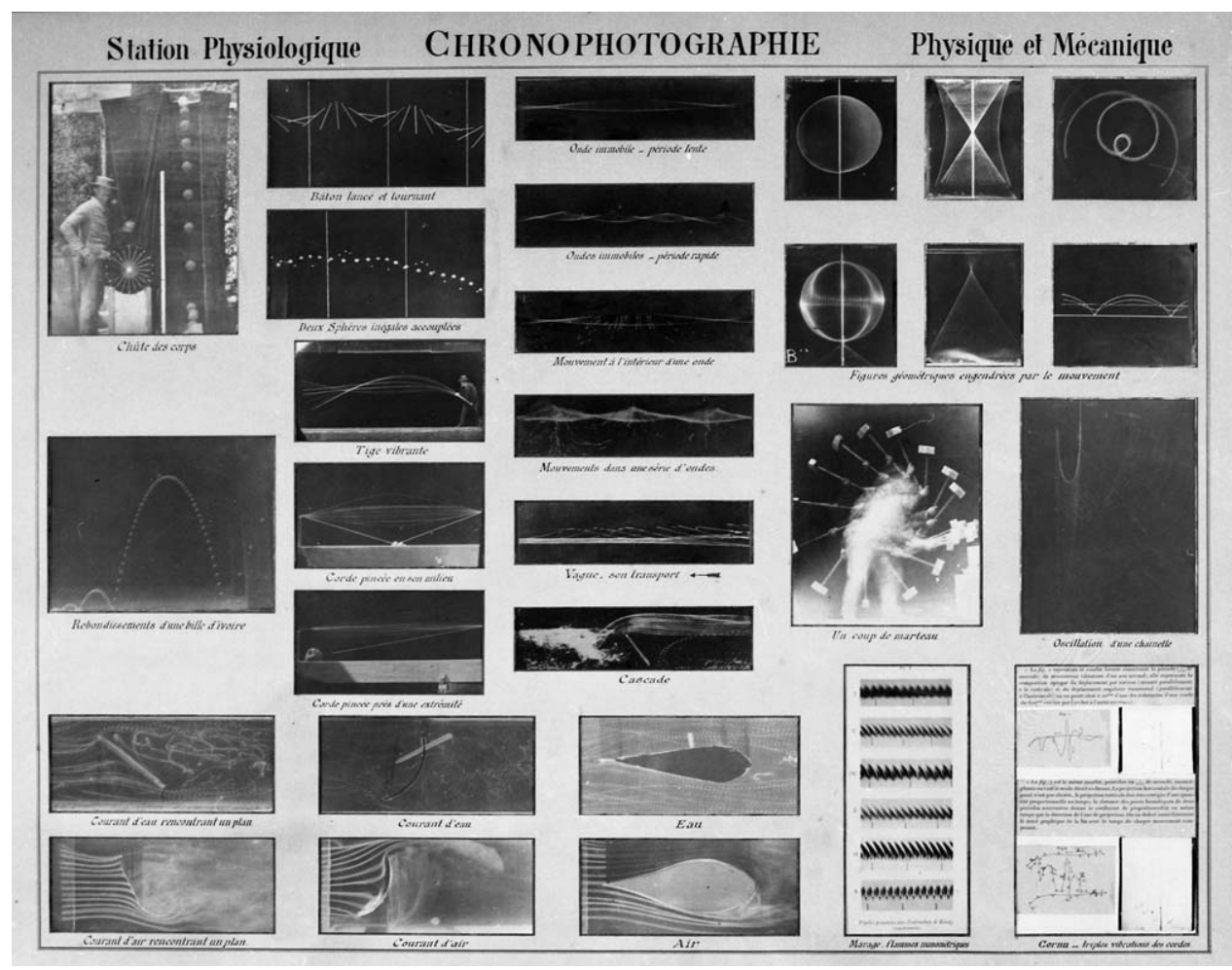

FIGURE 8. Etienne-Jules Marey, "Chronophotography, Station Physiologique, Physique et Mechanique," 1900, poster for the World's Fair, Musée Marey, Beaune, France. Etienne-Jules Marey, Physique et Mécanique, chronophotographies, ensemble monté pour l'Exposition Universelle de 1900, Dépôt du Collège de France en 1955, Musée Marey, Beaune, France. Photo: J.-D. Lajoux.

If Marey had not been successful in linearizing and in narrowing the movements in his wind tunnel, he would have been forced to give up despite his enormous repertoire of methods.

(c) The addition of a chronograph. However, it was not Marey's inclination to surrender too quickly. His further research focused on change in the indicator of movement. In his last wind-tunnel type of 1901, Marey could change between two programs: the smoke fillets were either aspirated downward in smooth streaks (see fig. 1) or with an undulation (see fig. 9). The latter is realized by adding an electrically controlled chronograph and slightly shaking the tubes at the rate of ten times per second. Previously Marey had put considerable effort into calming the air in the container of the wind tunnel with silk gauges and nozzles in order to be able 


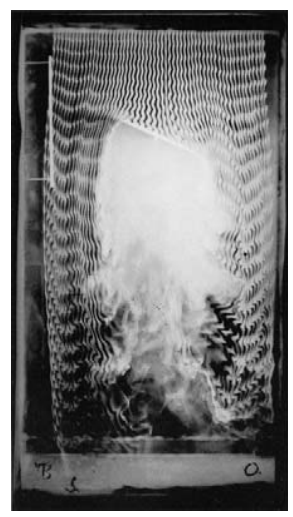

FIGURE 9. Etienne-Jules Marey, photograph of wind tunnel, with 57 injectors, with shutter function, 1901. From Georges Didi-Huberman, Laurent Mannoni, Mouvements de l'air, Etienne-Jules Marey, photographe des fluides (Paris, 2004), plate xxix. Collection Cinémathèque française, Paris.

to study the development of turbulences under "sterile," preferably monocausal conditions. And now this: the purposeful generation of an oscillation!

Science historians are right if they identify the vibrating element attached to the nozzles as a method of measuring time. ${ }^{49}$ This invention of Marey's speaks to the desire for further cues for analysis and quantification. Together the smoke fillets form a main direction-the vertical axisfrom which deviations to the left and right can be judged easily. If one wanted to optimize the ability to locate the phenomena, one would apply a kind of coordinate plane (for example, graph paper), that is, one would add other rows of lines at right angles to the already existing ones. The simplest way to get such a grid structure is to interrupt the longitudinal stripes in equal time intervals and thus to place simultaneous dots in a row. In all likelihood, it proved too difficult for Marey to create precisely contoured smoke dots in the air, however. His ultimate technical solution was to leave the vertical streaks unbroken, so that only the indentations in them mark the time impulses. Nonetheless, with this solution, which included a ruler placed on one side, Marey was able to gain certain insights into velocity rates in different regions.

The hypothesis that Marey tried to apply not only a lined pattern but also a checked one, and thus to put in disparate markers, takes on some weight when we look at his preliminary studies in hydrodynamics (fig. 10). Here he realized some chronophotographs of the movements of waves in water by using small, silvered, wax and resin balls..$^{50}$ For the studies of aerodynamics he had thought of something similar, but due to low air resistance he could hardly attain the analogously advantageous compactness of the resin pearls. In principle Marey—and after him Ahlborn—realized a punctual marking in water, both aiming at dotlike entities rather than lines.

Much later, Marey's idea was perfected, for example by F. A. Schraub and his collaborators (fig. 11). ${ }^{51}$ In 1965, they published their hydrogen- 


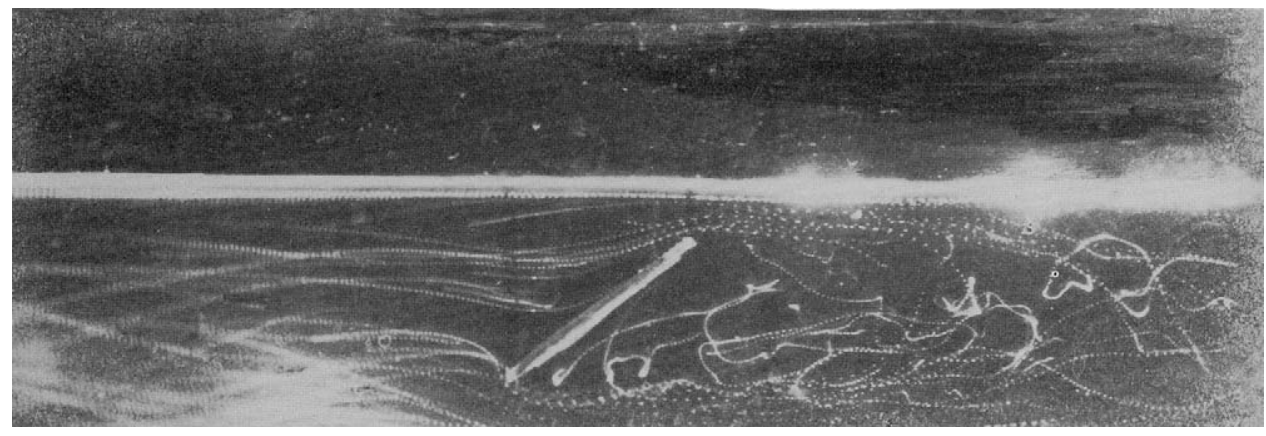

FIGURE 10. Etienne-Jules Marey, chronophotograph showing the movement of pearls in a liquid meeting a flat obstacle, 1893. From E.-J. Marey, 1830/ 1904: La Photographie du Mouvement (Paris, 1977), 54. Collection Cinémathèque française, Paris.

bubble method, in which a fine wire, as one end of a DC circuit, is used to electrolyze water at regular intervals. As a consequence the density of the tracer material is less than the density of the fluid whose motion is made visible. The German aircraft engineer Alexander Lippisch also seemed to build upon Marey's approach when recording the velocity distribution around a wing model (fig. 12). He placed nonrecurring, distinct parallel impulses and then fixed them chronophotographically with four short exposures. "Since the puffs at each tube were released at the same time, the line at any station of the test field represents the position of particles of the initial parallel flow after a certain lapse of time." ${ }^{52}$ Figure 12 was designed to study the conditions of ascending lift. This kind of depiction provides acceptably thorough insights when already streamlined model wings are used, but not in cases where massive turbulences are created. Thus, the resolution in figure 12 would not have been satisfactory for Marey. Moreover he would not have stopped at this stage but would have wanted to attach his proven diagrammatic analysis. For this he needed differences along the course of the smoke. Only with a checked raster encoding the "equitemporality of the occurrences" could Marey have returned to his proven graphical depiction. ${ }^{53}$ In this case, he would have diagrammed the links between photographed smoke dots of "equal age" with lines in order to achieve a more accurate representation (fig. 13). Such diagrams would have made areas of acceleration or deceleration visible. After the transition from the graphical to the (chrono)photographical method, then, Marey would have again needed a more fundamental transformation of his rich repertoire of measures in order to adequately determine air movements. 

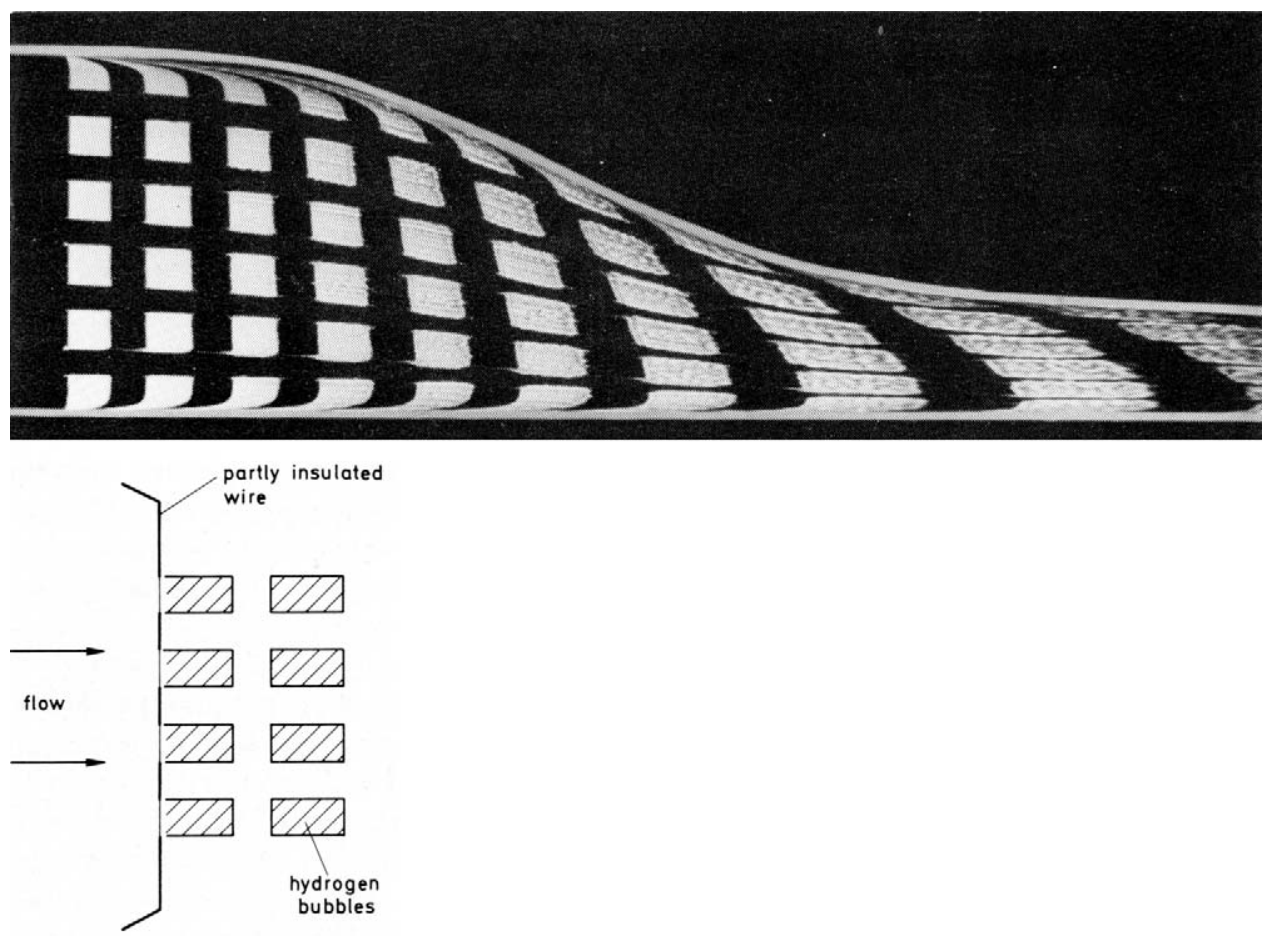

FIGURE 11. F. A. Schraub et al., photograph and schematic representation of the time-streak marker technique applied to flow in a contraction, ca. 1965. From Wolfgang Merzkirch, Flow Visualization (New York, 1974), 43, fig. 2.20 and 2.21. Courtesy of Wolfgang Merzkirch.

\section{Case Study II:}

\section{Friedrich Ahlborn's Water Channels}

We now come to the second case study. As I have already mentioned, Friedrich Ahlborn saw that air posed too many drawbacks as a research substrate, and thus he decided to conduct his experiments-also those relating to airplanes-in water basins (fig. 14). In 1901, Ahlborn built his first water tunnel, at a length of approximately two meters. He mounted rails that ran the length of the basin, upon which a motorized car could run, and used a weight to regulate the traveling speed of the car. A bracket attached to the car was immersed in the basin and served as a mount for the particular resistance object or obstacle, which was carried through the still water. The camera could be mounted either to the traveling car (that is, in a fixed relationship to the obstacle) or to the edge of the basin (in a fixed 


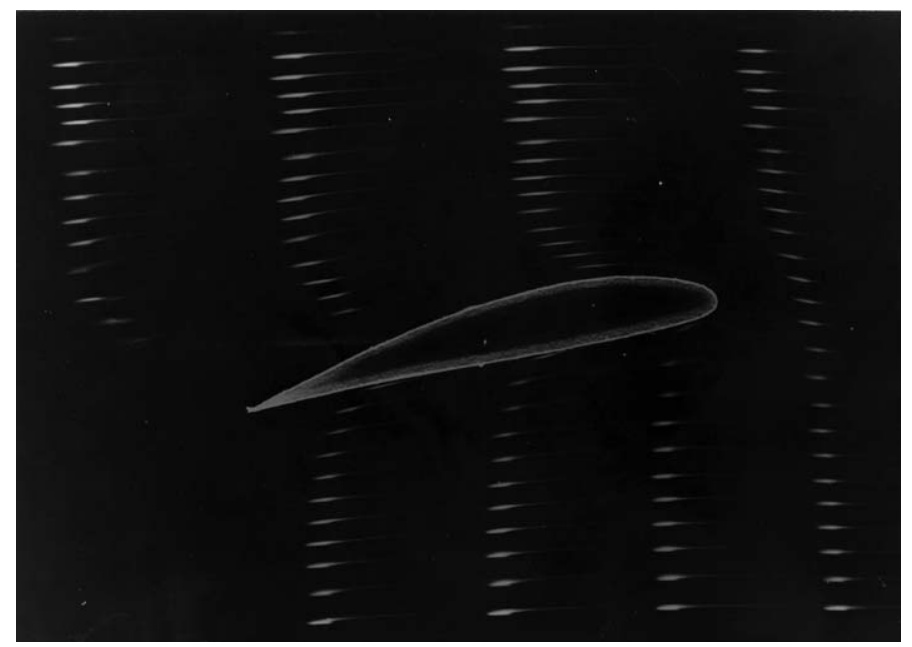

FIGURE 12. Alexander Lippisch, four exposures of a smoke front as it passes over a wing section operating at high lift, ca. 1956. From Henry V. Borst, The Aerodynamics of the Unconventional Air Vehicles of A. Lippisch (Wayne, PA, 1980), 1-15, fig. 11. National Air and Space Museum (NASM 9A08391), Smithsonian Institution.

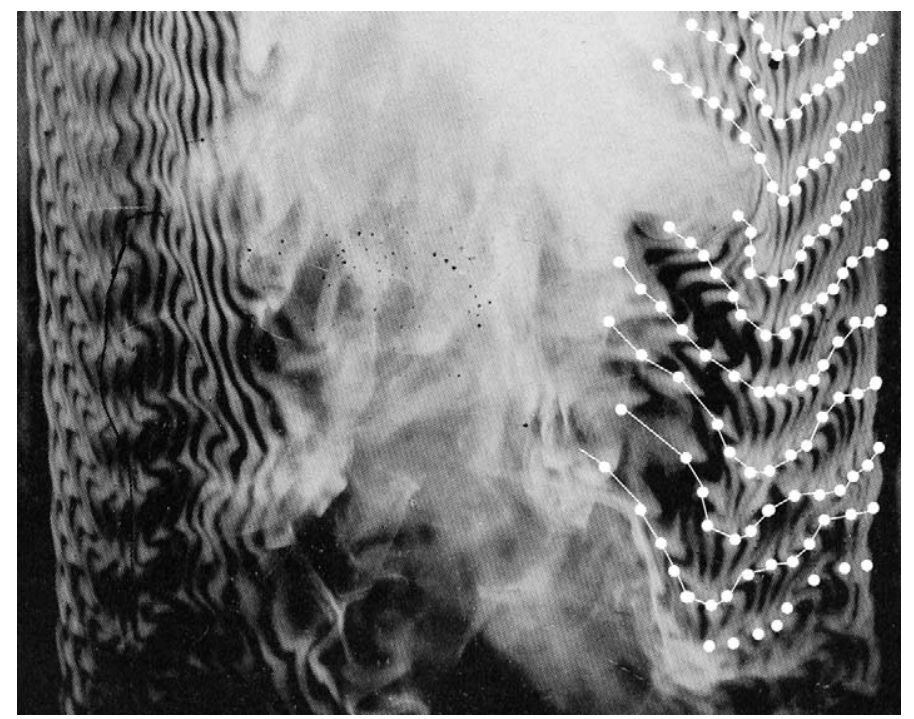

FIGURE 13. See fig. 9, reworked by the author. Collection Cinémathèque française, Paris. 


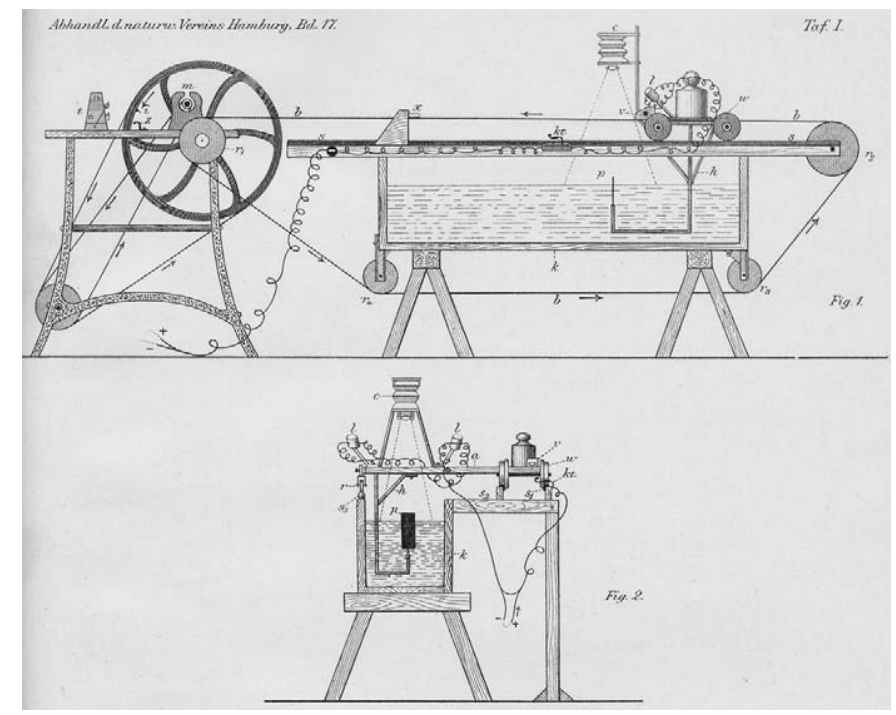

FIGURE 14. Friedrich Ahlborn, sketch of experimental setup for photographs of the water's surface with partially submerged obstacles, 1902. From Friedrich Ahlborn, Über den Mechanismus des hydrodynamischen Widerstandes (Hamburg, 1902), plate 1, figs. 1-2. L. Friedrichsen \& Co. Hamburg.

relationship to the calm water). In later attempts, he always placed two cameras with identical lenses side by side, so that comparable images could be made simultaneously with the static and traveling cameras. Approximately in the middle of its run, the car was to have accelerated to the desired speed. At that moment, it closed a circuit via an attachment to its rails, triggering the camera shutter and the flash. Due to this illumination and to the black-painted interior walls of the trough, the de-oiled club moss spores (Lycopodium) that had been strewn on the water's surface (fig. 15) were set off clearly from the background. If in Marey's setup the smoke fillets serve to make the turbulence visible and constitute a differentiated field, in Ahlborn's water channel the diffused, tiny club moss spores fulfill this same purpose. The difference is striking. How intensely must Ahlborn have wished for such an orderly array as the parallel smoke streaks in order to draw the flow lines. His British colleague Henry Selby Hele-Shaw observed "strong whirlpool action" in his own tubes and found it hopeless to study these to begin with. The wish he expressed with respect to the fluid is revealing and also holds for the tracer material. He wrote that a simpler situation "would be the case if the water flowed very slowly in a perfectly smooth and parallel river bed, when the particles would follow one another 


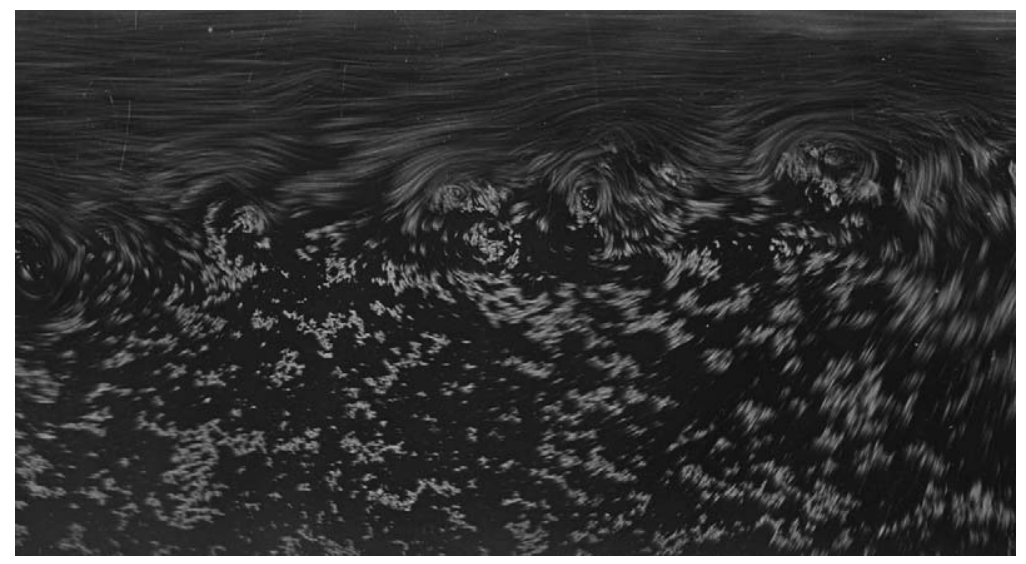

FIGURE 15. Friedrich Ahlborn, club moss spores (Lycopodium) on a water surface. Deutsches Museum Archiv, Bildstelle, Munich.

in lines called 'streamlines,' and the flow would be like the march of a disciplined army, instead of like the movement of a disorderly crowd, in which free fights tak[e] place at various points." ${ }^{54}$ But Ahlborn's club moss spores could not be brought into a regular formation; instead they arranged themselves on the water in tiny clumps of varying size-nothing like a homogeneous distribution. Thus, the whole setup could be considered problematic. ${ }^{55}$ Additionally, the exposure time was not long enough that a single spore-cluster could have left behind a streak through the whole photographic plate. Instead, Ahlborn was confronted with the next critical hurdle, namely, the production of lines in his drawings by using several recorded sections.

Various photographic modes. When using club moss spores it became clear that the choice of the exposure time played a crucial role in the streak formation on the photograph. But what did Ahlborn's recording technique look like exactly? For the water surface Ahlborn developed three different modes of recording (fig. 16) as applied processes of photographic flow analysis. These permitted the representation of the movement of fluids in the form of flow lines, force lines, and path lines. If the model was carried through the water, the static camera with a short exposure time recorded the system of force lines (the force field), but with a long exposure time it recorded the path lines. If the camera traveled together with the model, then the traveling camera with a long exposure time recorded the flow lines. "Due to the resting fluid while the photographic camera is moved, the swimming club moss spores produce[d] on the photographic plate a system 

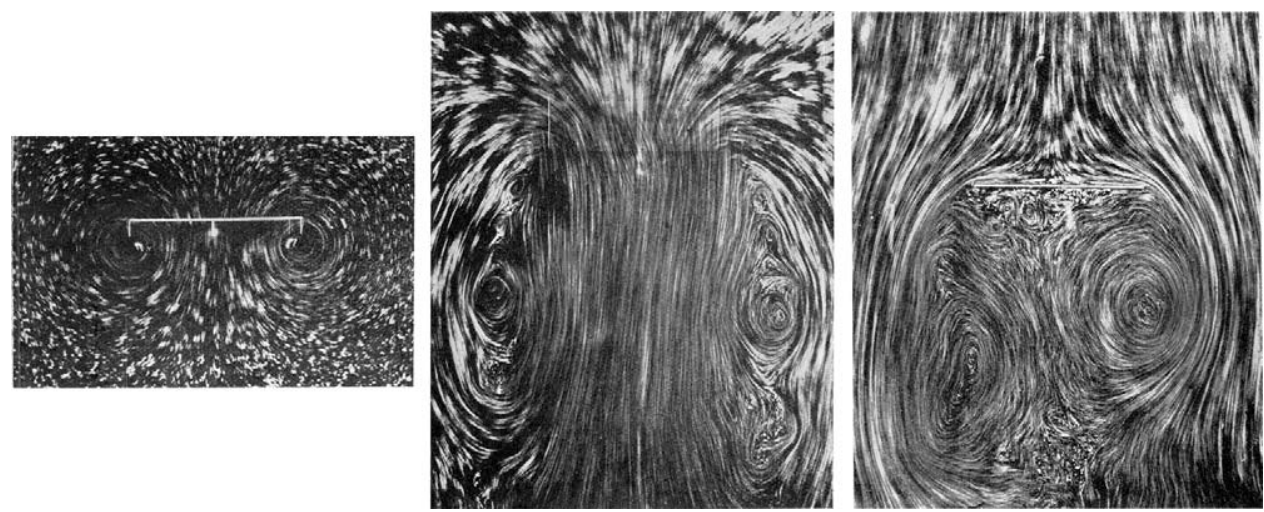

FIGURE 16. Ahlborn's techniques for photographic imaging of the water's surface: force lines (left), path lines (middle), and flow lines (right). From

Friedrich Ahlborn, "Strömung und Widerstand an Platten," Flugwesen 10, no. 7 (1930): 77-78.

of fine lines-their length depending on the exposure period-through which the direction of currents in the fluid is shown in every detail, with greatest clarity. ${ }^{56}$ We name these lines flow lines and regard the obtained photographic images as what they seem to be, namely as views of a movement of a stream of liquid against a resting body." 57

In order to really understand what was to be seen, the researcher had to mentally assume the position of the camera and combine the type of movement with the mode of recording. The photographs from the static and traveling cameras showed "so utterly deviating and, at first, surprising flow images, that for the uninitiated it would seem impossible to demonstrate the correspondence of the events [thus] represented." ${ }^{58}$ Each of the modes of recording offers a different view of the same phenomenon and thus exposes different facets of it. It is not easy to comprehend that one sees always the same-but differently.

The force lines are to be imagined as a system of rigid lines, which remains in a fixed connection with the model-the obstacle-no matter whether the latter persists in the flow or is carried through the fluid. The lines denote the direction of the velocity at each position of the force field. No liquid particle goes along the force lines ... but moves in the force field passing by only momentarily into the direction of the force line by which it is crossed just in that moment and which it has already abandoned in the next instant. ${ }^{59}$

Thus, the particles travel not along the force lines, but along the flow and path lines (see fig. 17). The path lines are nothing other than flow lines deprived of the translational movement of the original parallel flow. 

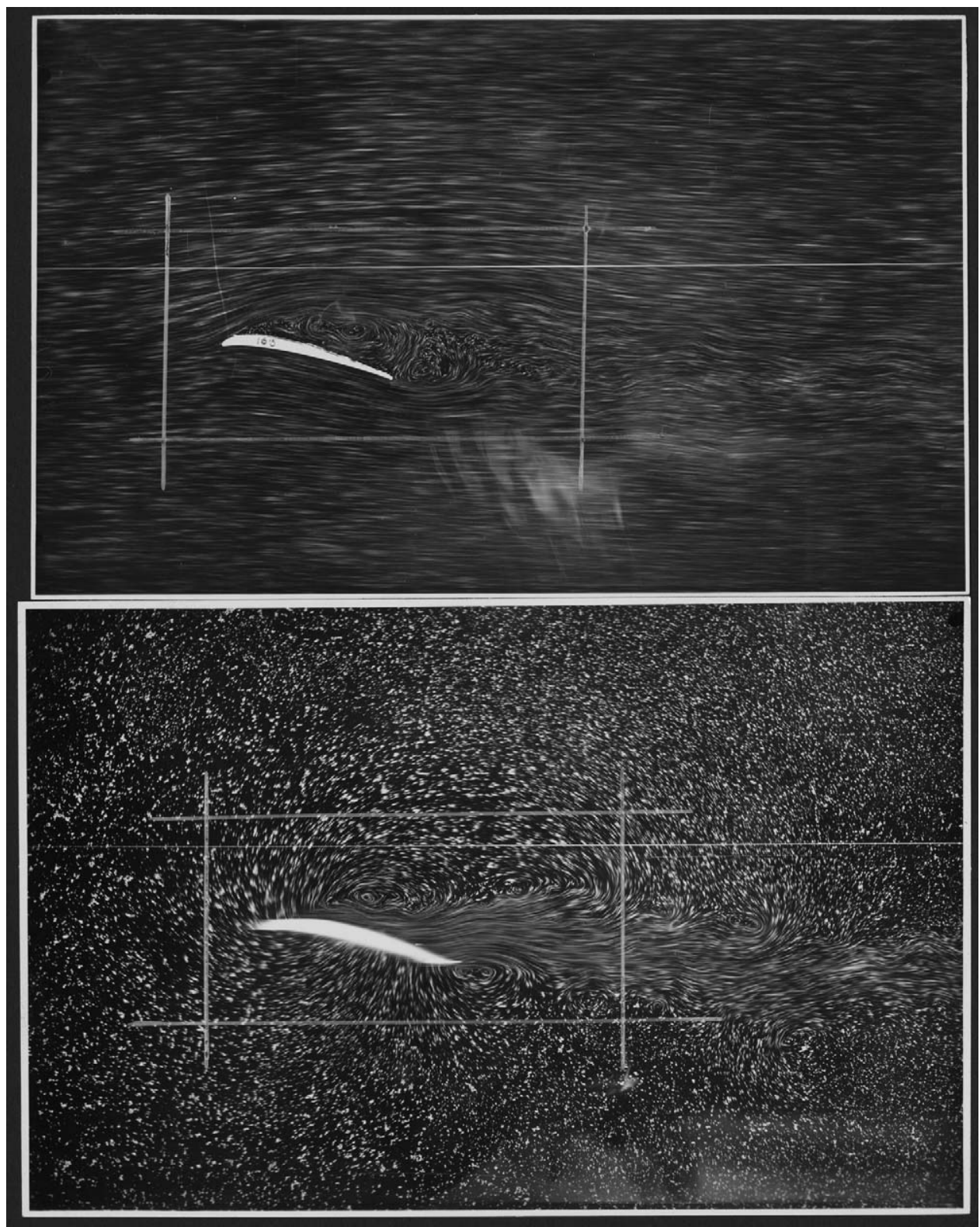

FIGURE 17. Friedrich Ahlborn, photographs of a hydrodynamic experiment with traveling camera creating flow lines (top) and stationary camera creating path lines (bottom). Deutsches Museum Archiv, Bildstelle, Munich. 
While Marey obtained precise lines only with a short exposure time, Ahlborn obtained them with a longer exposure period. Considering the situation more closely, its complexity becomes apparent because with complementary images Ahlborn achieved zones of clarity, but also zones of blurring. However, the latter were not the product of mixing materials, as with Marey's images; they were the result of areas of overlap that were caused by the recording technique, but which proved to be indispensible for making the different zones visible. Ahlborn needed indicators in the shape of points because he could use them to represent movement (which can be detected as lines), together with areas in which no movement occurs (which can be detected as points-and not just in the short exposures). ${ }^{60}$ This means that to have used lines from the outset would have been a disadvantage in terms of his desire to separate these zones optically. Through the splitting of the phenomenon, he created a space for experimentation. Ahlborn used his photographs to give structure to the phenomenon, and he achieved further elucidation through his schematic drawings. With the magnifying glass in his hand, Ahlborn studied his photographic plates scrupulously, "What do the photograms teach us about the resistance?-In order to answer this question, we want to extract the essence from the recordings in the form of the schematic depiction we obtain if we draw a system of equally spaced parallel lines in the primary direction through the unaffected part of the flow in front of the obstacle and furthermore to allow this system to follow the photographic lines of flow exactly." ${ }^{1}$ To begin with, it becomes clear that Ahlborn mentally proceeds from the unaffected flow to the turbulent zone.

The premise of charting idealized flow lines in identical intervals can be seen as quite presumptuous, because one does not get any hint as to how to determine the distances between them in the photographs (see fig. 18). And then which of the short section traces are to be followed? How useful a continuous line would be. Instead, Ahlborn has only vectors at his disposal, which "to the eye appear as parts of connected flow lines." ${ }^{62}$ But by drawing detached lines he creates space so that he is able to overlap different schemes.

The graphical translation. All structuring procedures can be seen as efforts to make something determinable. Let me recall Ahlborn's own definition of turbulence: "Under turbulence in general one understands a disorderly mess of eddy-like movements, the form, rotational direction, and force of which are fluctuating and indeterminate." ${ }^{63}$ At first glance, conditions in the turbulent zones are not at all revealing. The following description provides an impression of the events' temporal component: 

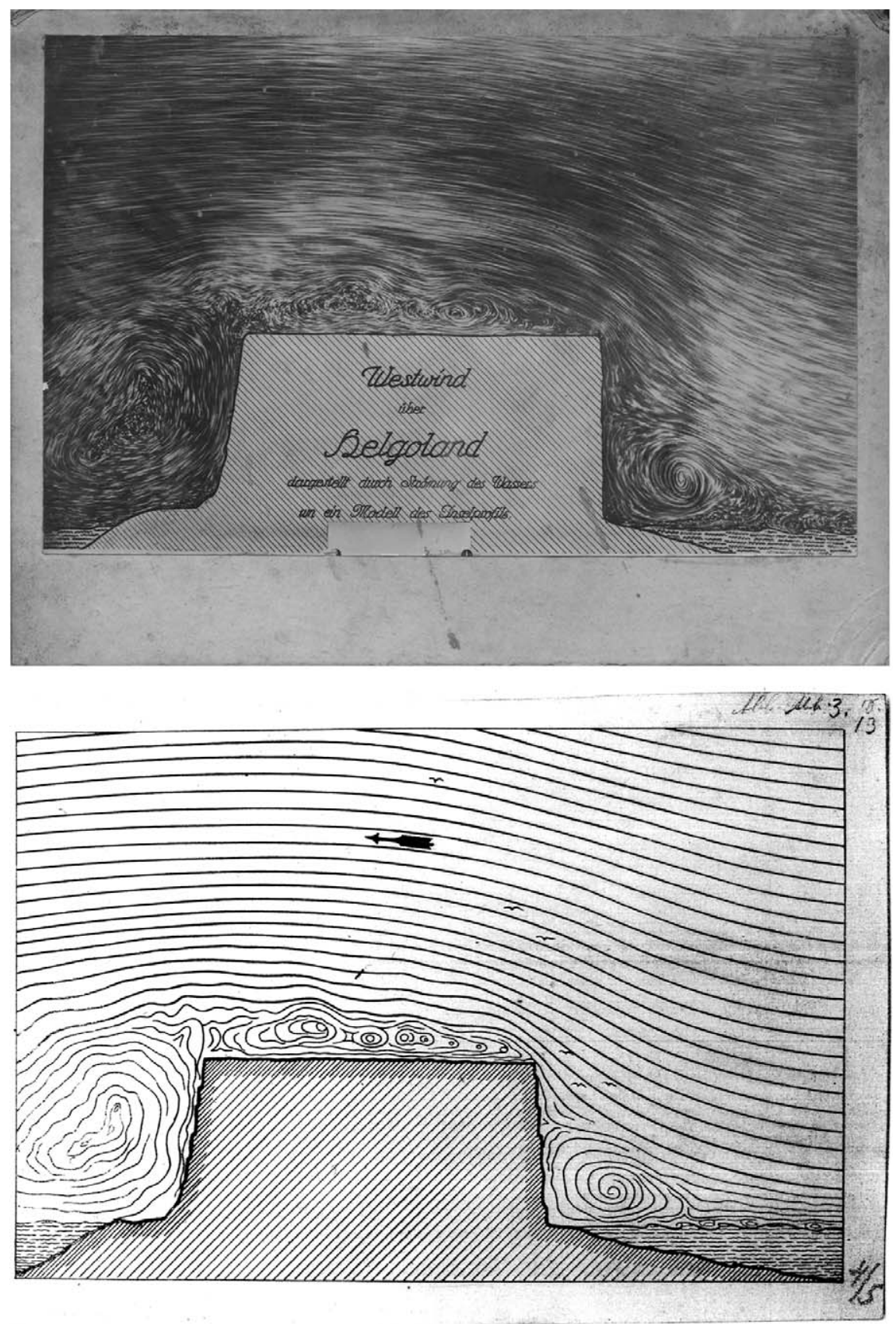

FIGURE 18. Friedrich Ahlborn, West Wind at Heligoland. Flow-line photograph (top) and flow-line diagram (bottom). Deutsches Museum Archiv, Bildstelle, Munich. 
The fluctuations in the proceeding of the dragwater's flows are very conspicuous. ... Already in the normal positioning [that is, orthogonal to the flow] of the plate a nearly perfect symmetry of the vortices is hardly ever given in single moments. The photograms always show some, at times quite striking, irregularities. Sometimes the one, then the other vortex branch is more strongly developed, more rounded or protracted; sometimes they come closer to the plate, sometimes they hang a bit behind and leave a relatively calm, temporarily nearly stagnant dragwater behind the plate. Accordingly, the wake is also unstable in the direction and velocity of its movement. This is why one mostly sees quite diverse flow images on photographic plates, the recordings of which were exposed shortly in succession twice, and one realizes how fast these fluctuations take place. ${ }^{64}$

From this description it is evident that the graphic translations do not mirror any specific situation but are saturated by the researcher's pool of experience. Ahlborn "cleared" the situation for more concision and adjusted the schemata according to symmetry. He openly admitted that the various elements of his drawings were made with recourse to several photographs. ${ }^{65}$ With the transcription of these photographs into line diagrams, Ahlborn succeeded in exposing the processes. Through the combination of different types of lines from the same scenario, he could find diverse correlations, explain some structural connections, and also give more thorough explanations or instructions. ${ }^{66}$ For Ahlborn the drawings turned out to be highly productive. Without going into his scientific results, I focus instead on how Ahlborn uses the line. Figure 19 is an example of the combination of various kinds of lines (flow lines and force lines) representing one situation, whichas mentioned-presuppose different kinds of photographic recordings. With this diagrammatic overlay of two different kinds of lines representing the same situation Ahlborn is able to distinguish discrete areas of activity. The flow lines are shown as lines throughout the diagram and without arrows. The force lines, with arrows, depart more or less in the opposite direction. However, in favor of clarity, Ahlborn refrains from representing the entire force field in the area behind the obstacle. Due to the slant of the plate, the "gyromes" (Greek for "rounded," "swirl") turn out different in size, but they are clearly detectable. ${ }^{67}$ From their respective centers, some curved dotted lines reach out, suggesting the differences in the water level's vertical height. Furthermore, one sees the stern wave $\left(\mathrm{W}_{2}\right)$ behind the vortices, as well as the bow wave $\left(\mathrm{W}_{1}\right)$ in front of the resistance object. The line $A$ impacts the front side of the disk where the water separates when flowing around the obstacle, representing the front pressure maximum. This zone should be readable from the ideal (drawn) flow lines, as it is identical with the positions where these lines are the greatest distance from each other. In order to understand how the pressure of the water is linked with the distance between the drawn lines it is necessary to consider Ahlborn's frame of reference. 


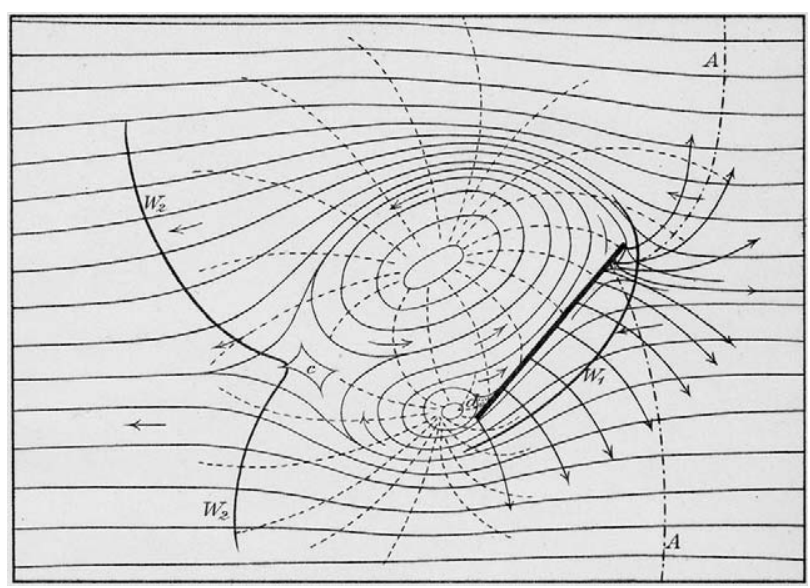

FIGURE 19. Friedrich Ahlborn, combination of flow lines, force lines, water-level data, and bow and stern waves, 1904. From Ahlborn, Über den Mechanismus des hydrodynamischen Widerstandes, plate 3, fig. 8. L. Friedrichsen \& Co, Hamburg.

Depiction from hydrodynamics and magnetism as models. Ahlborn started with concepts completely different from Marey's. With lines he divided the water into sections; that is, he likely first chose the interval that would be suitable for observation arbitrarily (as did Marey) and then decided which amount of water he wanted to conceive as a "unit." ${ }^{68}$ Of his diagrams Ahlborn wrote, "Each of the bands lying flat between two neighboring lines then represents an elementary flow or flow thread, and we can imagine that the water flows in it as in a pipe if we disregard the friction." ${ }^{69}$ He referred to mathematician Daniel Bernoulli's 1738 theorum signifying that in a steady flow the sum of kinetic and potential energy remains constant. The same amount of water passes faster and with less pressure through thin tubes than through larger ones (see fig. 20). By analogy, in Ahlborn's diagrams, diverging flow lines mean less velocity and more pressure; converging lines represent the opposite. "With the help of this key we are able to read and to understand the documents of the flow images." 70 To be more precise, with this "key" it is possible to convert the photographs into his schemata. Neither kind of depiction fully coincides with the other because the following statement, for example, holds only for the photographs: "The length of the lines is the measure for the flow velocity at any point of the field of resistance."71 Between the distance covered by the photographed club moss spores in a known exposure time interval on the one hand and the distance between the drawn flow lines on the other, there exists a negative correlation: the longer the club moss spores' traces, the narrower the distance between the 


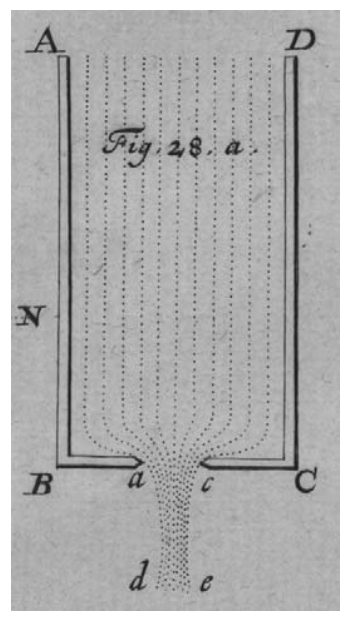

FIGURE 20. Daniel Bernoulli, water flow in converging (or diverging) tubes, 1738. From Daniel Bernoulli, Hydrodynamica (Strasbourg, 1738), plate 4, fig. 28a. University Library of Basel, shelfmark Jt II 7.

drawn lines. In one instance the velocity is given in the logic of camera technology, in the other in the logic of the traditional custom of depiction.

Besides Bernoulli, Ahlborn referred to other sources to ground his conceptualization of flow and its graphical representation. Again and again he took up the representations of ideal potential flow by Leonhard Euler. A further point of reference was the work of the British naval engineer William Froude. Because of their analogue qualities and the geometric similarity, Ahlborn relabeled the "absolute flow lines" "force lines."72 Consistent with his rejection of the traditional (because misleading) nomenclature, he borrows his term from the field of electromagnetics. The work of the English physicist Michael Faraday, especially, turned out to be influential, as Faraday isolated structures by spreading iron fillings in a magnetic field (thereby following Peter Barlow and others).

According to science historian David Gooding, after 1850, when Faraday had already developed his field theory, he started elaborating and defending this "theory of lines": "Lines emerged from these patterns, partly because lines were already available and a proven means of structuring sensory experience, and partly because of Faraday's particular interest in the explanatory potential of a link between vibrations and 'striations." 73 Faraday regarded lines as a necessary method of differential observation for determining differences of the magnetic influence on various (para- and diamagnetic) substances (fig. 21). Here too the deviation of the lines from perfect parallel alignment coded what was essential, and thus the conceptual basis of the field as already figured with lines in a differentiated space was indispensable. Faraday's method of observation of magnetic features builds on the possibility of detecting differences in the magnetic influence on various substances in a magnetic field: 

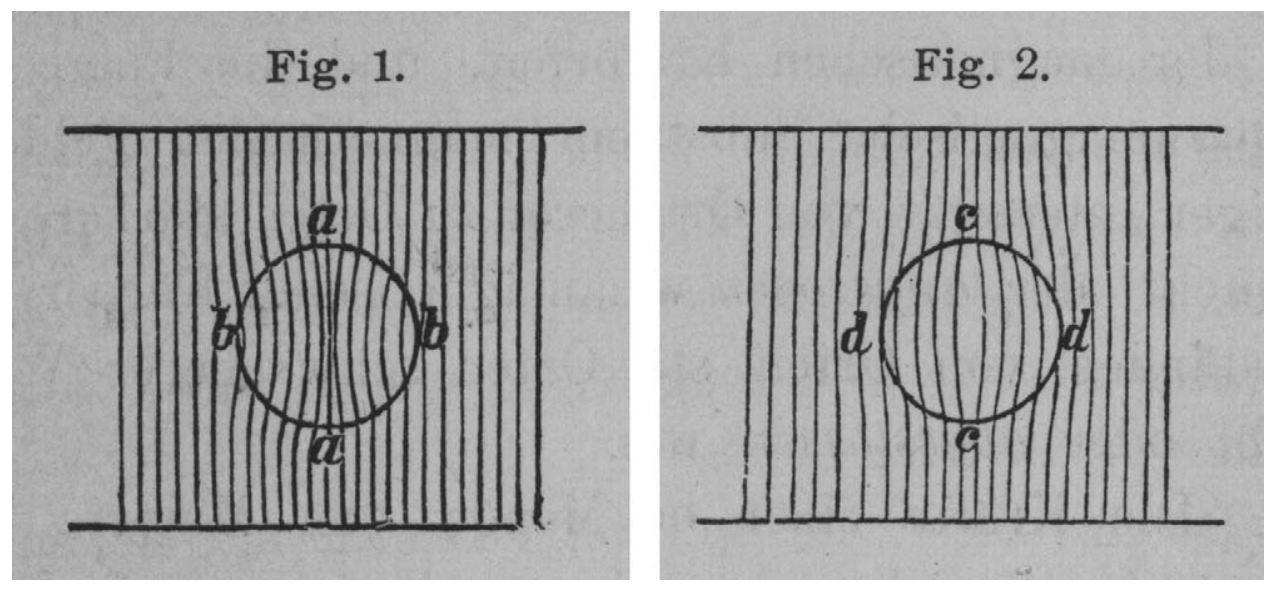

FIGURE 21. Michael Faraday, simplified depiction of paramagnetic and diamagnetic matter with respect to "mere space," 1851. Fig. 1: convergence; fig. 2: divergence. From Michael Faraday, ExperimentalUntersuchungen über Elektricität [1855], (Berlin, 1891), 3:\$2807, fig. 1-2. University Library of Basel, shelfmark Jv IX 32:3.

This method of [differential] observation required lines because Faraday had represented the effect in terms of changes in the density of lines. The "converging" of magnetic lines by the "concentrating action" of iron made clear a practical understanding of the experimental techniques of the 1820s. Faraday now claimed that it was impossible to interpret his results in any other way. He stated emphatically that "no other method [of representation] could be used with the differential system of observation." "74

The main features are again encoded in the converging of the magnetic lines. So, for his flow lines, Ahlborn found in Faraday the idea of the "distortion of lines" already preformed. I restrict myself to mentioning just a few precursors in order to suggest that Ahlborn contemplated his line formations with respect to the different intervals they have to each other. For him, the relative width of the pipe bundles was meaningful.

\section{Summary: Toward the Relationship Between Recorded and Drawn Lines}

In summary, we can say that neither of the two researchers limited himself to simply redrawing the lines recorded in photographs. The drawn lines are significant for both. As a starting base, in each case an ensemble of 
points has to be arranged in order to get the lines drawn as soon as time becomes relevant. With his lines, Ahlborn splits the water into different zones in order first to be able to define structures, second to code velocity and pressure, and third to situate his brilliant narrative descriptions. With the narration of the events he could describe the single parts at length, stretch the time so the processes could unfold in front of the reader's inner eye. In his eloquent description, Ahlborn gave the impression that he could observe what happened when the obstacle changed its direction in the water. In other words, he envisioned an interactive handling, though one has to suspect that during the actual experiments-lasting only a few seconds-the immersed resistance object always remained in the same orientation.

Marey too is concerned with the tension between space and time, but differently. The relationship between the speed of the movement and the exposure time is a difficult issue in chronophotography on a fixed plate. If the object moves too slowly relative to the recording/exposure frequency of the camera, then its outer appearance is "drowned out" by the quantity of information. However, this can still be puzzled out as long as a progression is recorded. According to Jean-Luc Daval, the segmentation of the movement into many small spatiotemporal units puts the emphasis on the measurement of distance by way of time. ${ }^{75}$ Bernd Stiegler interprets the focus the other way around: "All of Marey's experiments have in common that time is converted into space and is readable in spatial categories. Pontus Hultén describes this procedure as "transcribing an idea of time in terms of space." $" 76$ With his spatiotemporal inquiries, Marey ultimately points to the calculation of the expenditure of energy. The comparison between Marey's visualizations of flow and those of Ahlborn shows a related approach in many respects. From their hints regarding requirements and claims one can conclude that both scientists pursued their research in accordance with what later will be called "mechanical objectivity."

They were committed to establishing standard requirements for instruments and results, as well as to recording phenomena with as little disturbance or influence from extraneous factors as possible; or-even better-to let the phenomena inscribe themselves. ${ }^{78}$ The provisions for making things visible should solely and clearly reveal the existing situation. Even though the approaches seem to be quite similar at first, upon closer examination substantial differences become apparent.

One significant difference between Marey's and Ahlborn's approaches lies in the meaning of longitudinal coding. Or, to put it in other words, Marey thinks along the lines and would have had in mind a portrait of the successive advance of the mobile wall of streaks, while Ahlborn thinks more across the lines. ${ }^{79}$ What must be noted here is the relative width of the tube bundles between the flow lines, which here function as partition markers. 
While the bright striations of the club moss spores in the photographs serve as local velocity indicators, and thus their lengths are information carriers, the length of the flow lines in Ahlborn's drawings does not encode anything further. The drawn lines fill the whole image in such a way that, for Ahlborn, a proceeding "front" is not urgently desired. Therefore, in his schemes no past is depicted. He composes an average impression of a fully developed movement. In fact, there exist sporadic drawings depicting nascent vortices. However, Ahlborn then presents this genesis in separate drawn stages, and these graphics are not to be misinterpreted as the representation of a specific development of eddies. Such "portraits" are rather to be expected from Marey.

The field of lines cannot be restricted to something merely formal or material. Marey and Ahlborn understood it also within their specific horizons of rehearsed practices, customs, situating factors, and theoretical frameworks. The images are undoubtedly affected by the scientific culture. To modify W.J. T. Mitchell's dialectical concept of visual culture: while images can be seen as social constructions, the inverse perspective is also evident, namely, that-in this case-the sciences are shaped insofar as they are partly based on the visual and on visualizations. ${ }^{80}$ The images that result from research in turn shape further research and the design process. This is not always uniformly the case, but I have attempted to give some indication, by way of example, of how and to what extent artifacts of research can foster, inhibit, or channel actions directed toward a scientific outcome.

\section{Notes}

Benjamin Smith edited this essay for language use. Unless otherwise noted, all translations are my own.

The two archives from which most of my research has derived are identified here by the following abbreviations:

PAK Philosophisches Archiv of the University of Konstanz

DMA Deutsches Museum Archiv Munich

(Within the DMA, the dossier of Friedrich Ahlborn is referred to as NL 091, the dossier of Ernst Mach as NL 174; and the dossier of Ludwig Mach as NL 179.)

1. Bruno Latour, "Circulating Reference: Sampling the Soil in the Amazon Forest," in Pandora's Hope: Essays on the Reality of Science Studies (Cambridge, MA, 1999), 24-79, here 69.

2. Ibid., 56 . 
3. Marcel Boumans, "Built-in-Justification," in Models as Mediators: Perspectives on Natural and Social Science, ed. Mary S. Morgan and Margaret Morrison (Cambridge, 1999), 66-96; here 91-93.

4. Evelyn Fox Keller, "Models Of and Models For: Theory and Practice in Contemporary Biology," in "Proceedings of the 1998 Biennial Meetings of the Philosophy of Science Association. Part II: Symposia Papers," supplement, Philosophy of Science 67 (September 2000): S72-S86.

5. A strong statement for operativity is given by William Wimsatt, who explains to what extent false models can nonetheless be useful. By calling them "false models," or theories, he means that they lack realism and fail as correct descriptions of the world. If they are nonetheless useful, this must be independent of or at least not solely a product of how well they represent the world. The falsity of a model is often essential to its role. They are false because incomplete, idealized, and only locally applicable, and they misdescribe the interactions or presuppose a number of entities that do not exist. After listing to what extent models can be false, Wimsatt nonethess adds twelve ways of applying them gainfully. In short, the function of representation and the function of operativity can diverge in a single model. See William C. Wimsatt, "False Models as Means to Truer Theories," in Neutral Models in Biology, ed. Matthew Nitecki and Antoni Hoffman (New York, 1987), 23-55. William C. Wimsatt, "Using False Models to Elaborate Constraints on Processes: Blending Inheritance in Organic and Cultural Evolution," Philosophy of Science 69, no. S3 (September 2002): S12S24.

6. See Sybille Krämer, “Operative Bildlichkeit. Von der 'Grammatologie' zu einer 'Diagrammatologie'? Reflexionen über erkennendes 'Sehen,'” in Logik des Bildlichen. Zur Kritik der ikonischen Vernunft, ed. Martina Heßler and Dieter Mersch (Bielefeld, 2009), 94-122.

7. On graphical recordings see Robert Brain, "The Graphic Method: Inscription, Visualization, and Measurement in Nineteenth-Century Science and Culture" (PhD diss., University of California, Los Angeles, 1996). Joel Snyder, "Visualization and Visibility," in Picturing Science, Producing Art, ed. Peter Galison and Caroline A. Jones (New York, 1998), 379-97. On the running pictures see, for example, Marey/Muybridge, pionniers du cinéma: rencontre Beaune/Stanford; actes du colloque, 19 May 1995, Palais des Congrès, Beaune (Beaune, 1996). PierreJean Borey compares four aspects of technical problems that Marey transformed in his revolving-disk cameras with four main types of filmic montage; see Pierre-Jean Borey: "Vie et mort dans l'image, de Marey à Marker," in Marey, Penser le Mouvement, ed. Christian Salomon (Paris, 2008), 113-39. On motion-capture technologies see Edwin Carels, "Biometry and Antibodies: Modernizing Animation/Animating Modernity," in Animism, ed. Anselm Franke (Berlin, 2010), 1:57-74. Eric S. Faden, "Chronophotography and the Digital Image: Whoa ... Déjà vu!" in Arrêt sur image, fragmentation du temps/Stop Motion, Fragmentation of Time, ed. François Albera, Marta Braun, and André Gaudreault (Lausanne, 2002), 335-45. The art historian Noam M. Elcott is currently working on the black screen.

8. See Françoise Forster-Hahn, "Marey, Muybridge, and Meissonier: The Study of Movement in Science and Art," in Eadweard Muybridge: The Stanford Years, 1872-1882 (Stanford, 1972), 85-109 (Stanford University Museum of Art 7. 10.-3.12.1972; E. B. Crocker Art Gallery, Sacramento 16.12.1972-14.1.1973: University Galleries, University of Southern California, Los Angeles 8.2.-11.3. 1973). 
9. Etienne-Jules Marey and Georges Demenÿ, Etudes de physiologie artistique faites au moyen de la chronophotographie. Première Série, vol. 1, De mouvement de l'homme (Paris, 1893).

10. Paul Souriau, La suggestion dans l'art (Paris, 1893).

11. Marta Braun, Picturing Time: The Work of Etienne-Jules Marey (1830-1904) (Chicago, 1992), 264-65.

12. Ibid., 264.

13. François Dagognet, Philosophie de l'image (Paris, 1984), 75.

14. An early account was written by Pierre Noguès, Recherches experimentales de Marey sur le Mouvement dans l'air et dans l'eau (Paris, 1933), esp. 81-97.

15. See Etienne-Jules Marey, "Des mouvements de l'air lorsqu'il rencontre des surfaces de différentes formes," Comptes Rendus des Séances de l'Académie des Sciences 131 (July 16, 1900): 160-63. Etienne-Jules Marey, "Changements de direction et de vitesse d'un courant d'air qui rencontre des corps de formes diverses," Comptes Rendus des Séances de l'Académie des Sciences 132 (June 3, 1901): 1291-96. Etienne-Jules Marey, "Les mouvements de l'air étudiés par la chronophotographie," La Nature (September 7, 1901): 232-34. Etienne-Jules Marey, "Le mouvement de l'air étudié par la chronophotographie," Journal de Physique Théorique et Appliquée, 4th ser., 1 (1902): 129-35.

16. Laurent Mannoni, "Marey Aéronaute: De la méthode graphique à la soufflerie aérodynamique," in Georges Didi-Huberman and Laurent Mannoni, Mouvements de l'air, Etienne-Jules Marey, photographe des fluides (Paris, 2004), 5-86, here 53.

17. Hahn wrote a valuable contribution to the turbulence studies of Marey by including French philosophy (Michel Serres, Gaston Bachelard); see Daniela Hahn, "Tourbillons et turbulences. Zu einer Ästhetik des Experiments in Etienne-Jules Mareys Machines à fumée," ilinx 1, no. 1 (2009): 43-69.

18. Christoph Hoffmann, "Superpositions: Ludwig Mach and Etienne-Jules Marey's Studies in Streamline Photography," Studies in History and Philosophy of Science 44, no. 1 (2013): 1-11, here 10. Independently and in ignorance of one another's research, in our simultaneously written articles we came to similar conclusions with respect to Marey.

19. See Georges Didi-Huberman, "Der Strich, die Strähne," in Öffnungen. Zur Theorie und Geschichte der Zeichnung, ed. Friedrich Teja Bach and Wolfram Pichler (Munich, 2009), 285-99; here 287.

20. Biographical considerations can be found in Johannes Weissinger, "Friedrich Christian Georg Ahlborn," in Neue Deutsche Biographie, ed. Historische Kommission bei der Bayerischen Akademie der Wissenschaften (Berlin, 1953), 1:107-8. J. Georgi, "Professor Dr. Fritz Ahlborn, ein vergessener Pionier der Strömungsforschung," Abhandlungen und Verhandlungen des Naturwissenschaftlichen Vereins in Hamburg n.s., 2 (1957): 5-18. See also Peter Supf, Das Buch der deutschen Fluggeschichte (Stuttgart, 1956), 1:221-24. Inge Hinterwaldner, "Model Building with Wind and Water: Friedrich Ahlborn's Photo-optical Flow analysis" (forthcoming).

21. Friedrich Ahlborn, Dickes und dünnes Profil [Ahlborn-Kanal], October 1, 1925, typescript DMA/NL 091, vi-vii.

22. See Etienne-Jules Marey, "Le mouvement des liquides étudié par la chronophotographie," Comptes Rendus des Séances de l'Académie des Sciences 116 (January 16, 1893): 913-24, here 914. Revealing for Ahlborn's attitude toward the "unrealistic theory" are many of his articles' titles closing with the phrase "and the reality." 
23. See Ludwig Mach, [untitled], in Akademischer Anzeiger [der kaiserlichen Akademie der Wissenschaften in Wien] (July 13, 1893): 198-200. Ludwig Mach, "Über die Sichtbarmachung von Luftstromlinien," Zeitschrift für Luftschiffahrt und Physik der Atmosphäre 15, no. 6 (1896): 129-39. Besides the citations in the scientific articles, this link is proven by the personal correspondence. Ahlborn asked, obviously not for the first time, for photographic records from Ludwig Mach: "From the reading of the presentation [Ahlborn's, included in the letter to Mach] you will see how valuable your beautiful photograms are that you published with your work about the visualization of air flow lines. Unfortunately the images are very scaled down and you yourself mention that in the originals one sees more details than in the reproductions. For the accurate comparison of the flows in the water and in the air, however, it is of major importance to inspect all details closely.... For this reason I addressed myself to your father, Professor Dr. E. Mach, with the request to dispose of some photographs of the flying projectiles that I am especially interested in studying, as a loan"; Friedrich Ahlborn to Ludwig Mach, Hamburg, December 18, 1901, DMA/NL 174/0617, 3-4. See the previously mentioned letter: Friedrich Ahlborn to Ernst Mach, Hamburg, December 18, 1901, DMA/NL 174/0616. Three months later Ahlborn's thank-you letter for the receipt of the photographic plates followed: Ahlborn to Ludwig Mach, March 10, 1902, DMA/NL $179 / 023$. In the same year, Ahlborn returned the favor by sending some of his own negatives: Ahlborn to Ludwig Mach, Hamburg, November 14, 1902, DMA/NL 174/0618.

Two letters by Ernst Mach to his son attest to the fact that Marey was informed about Ludwig's work: "In Paris I was in a meeting of the Parisian Academy and I found the old acquaintances all together. Marey is very enthusiastic about the flow lines"; Ernst Mach to Ludwig Mach, Vienna, July 24, 1896, PAK. Some years later the son broached the subject again, to which Mach senior answered as follows: "In the year 1896 in Paris I personally handed a photograph of the air flow lines to Marey. Later he also got the treatise. In any case he completely forgot the matter because back then he was grieving for the death of his mistress. Additionally, he does not speak German and did not read the stuff. What he knows about us is provided to him by [the Russian philosopher and engineer Peter Klementich von] Engelmeyer"; Ernst Mach to Ludwig Mach, Vienna, December 11, 1900, PAK. In June 1901 Marey reviewed the works of Ludwig Mach: see Marey, "Changements de direction et de vitesse." See also Braun, Picturing Time, 409n38.

24. Marey tries in every possible way to introduce time into images, and he originally uses both terms: "The change in terminology that Marey undertook in the year 1887, from photochronography to chronophotography, was based on the awareness-due to the technological differentiation facilitated-of a transition from the 'chronography' (the graphical recording) with the means of photography to the 'photography of time' (chronophotography), which has a strategic focus on time and not on a phenomenon any more. In fact, the chronophotography on a fixed plate or on film has its authority for all sorts of movement as long as visible phenomena are present"; Michel Frizot, "Notation als graphische Darstellung und ästhetischer Sprung," in Notation. Kalkül und Form in den Künsten, ed. Hubertus Amelunxen, Dieter Appelt, and Peter Weibel (Berlin, 2008), 55-67, here 61. With the expression "photochronography," Ahlborn in turn emphasized the velocity measurement that was simultaneously registered on the photographic plate with sparks: "I succeeded in visualizing and automatically 
fixing the course of the flows ... down to the subtlest details on small models by the way of photographic and chronographic arrangements"; Friedrich Ahlborn, Vorschlag zur Errichtung eines Hydrodynamischen Instituts Wasserbau für Schiffahrt in Hamburg, Hamburg, July 8, 1903, manuscript, DMA/NL 091, 5. See Friedrich Ahlborn, "Über den Mechanismus des Widerstandes flüssiger Medien," Physikalische Zeitschrift 3, no. 6 (1901): 120-24, here 121. See also note 50 of this article.

25. Etienne-Jules Marey, Le vol des oiseaux (Paris, 1890), § 133. Ahlborn also leans on this principle of the equivalence of action and reaction, hence allowing an inversion.

26. Hahn, "Tourbillons et turbulences," 65.

27. Marey, "Des mouvements de l'air lorsqu'il rencontre des surfaces," 161.

28. See Marey, "Le mouvement des liquides," $923 \mathrm{n} 1$.

29. See Friedrich Ahlborn, Über den Mechanismus des hydrodynamischen Widerstandes (Hamburg, 1902), 30-31. Friedrich Ahlborn, Einrichtung zur Beobachtung und Photographie der Strömungen an der Unterseite Schwimmender Körper, undated, typescript, DMA/NL 091 h-73, unpaginated.

30. Marey, "Des mouvements de l'air lorsqu'il rencontre des surfaces," 161.

31. It is not only in Thomas Mueller's discussion of some historical wind channels that it becomes clear that the whole experimental setup is directed to photographic or filmic recording. Light (something bright, shiny, or self-luminous) and, as a counterpart, a dark background is an essential factor in the experiments dealing with turbulence. See Thomas J. Mueller, "On the Historical Development of Apparatus and Techniques for Smoke Visualization of Subsonic and Supersonic Flows," AIAA (American Institute of Aeronautics and Astronautics) Meeting Paper, no. 80-0420 (March 1980): 31-44. DOI:10. 2514/6.1980-420.

32. Ahlborn, Über den Mechanismus des hydrodynamischen Widerstandes, 11.

33. Friedrich Ahlborn, "Die Widerstandserscheinungen in flüssigen Medien," Illustrierte Aëronautische Mitteilungen. Deutsche Zeitschrift für Luftschiffahrt 8, no. 6 (1904): 185-99 and 231, here 186.

34. Friedrich Ahlborn, Strömungsbilder und ihre Erklärung, undated, 5. Labeled "Korrektur an Herrn Prof. F. Ahlborn," typescript, DMA/NL 091.

35. Friedrich Ahlborn, Ueber den Einfluss der Turbulenz auf Stroemung und Widerstand an Kugeln und Zylindern, undated, typescript, DMA/NL 091 a-2, 2.

36. Friedrich Ahlborn, "Turbulenz und Mechanismus des Widerstandes an Kugeln und Zylindern," Zeitschrift für technische Physik 12, no. 10 (1931): 482-91, here 483. See also Friedrich Ahlborn, Mängel der Windkanäle, undated manuscript, DMA/NL 091.

37. François Dagognet, Etienne-Jules Marey: A Passion for the Trace (New York, 1992).

38. John W. Douard, "Etienne-Jules Marey's Visual Rhetoric and the Graphic Decomposition of the Body," Studies in the History and Philosophy of Science 26, no. 2 (1995): 175-204, here 190-91.

39. See E. Hoff Hebbel and L. A. Geddes, "The Beginnings of Graphic Recording," Isis 53, no. 3 (1962): 287-324, esp. 293. Soraya de Chadarevian sounds a note of caution concerning the transferability of the graphical methods in different (for instance French and German) scientific cultures. See Soraya de Chadarevian, "Die 'Methode der Kurven' in der Physiologie zwischen 1850 und 1900," in Ansichten der Wissenschaftsgeschichte, ed. Michael Hagner (Frankfurt am Main, 2001), 161-88.

40. Wolfgang Schäffner, "Bewegungslinien: Analoge Aufzeichnungsmaschinen," in Electric Laokoon. Zeichen und Medien, von der Lochkarte zur Grammatologie, 
ed. Michael Franz et al. (Berlin, 2007), 130-45, here 141. For the quotations within the quotation, see Etienne-Jules Marey, La methode graphique dans les sciences expérimentales et principalement en physiologie et en médecine (Paris, 1878), 115 and 648.

41. Laurent Mannoni, "Die graphische Methode-eine neue Universalsprache," in Notation. Kalkül und Form in den Künsten, ed. Hubertus Amelunxen, Dieter Appelt, and Peter Weibel (Berlin, 2008), 325-30, here 326.

42. See Etienne-Jules Marey, "La chronophotographie. Nouvelle méthode pour analyser le mouvement dans les sciences physiques et naturelles," Revue générale des sciences pures et appliquées 2, no. 21 (1891): 689-719, here 690. Etienne-Jules Marey, La chronophotographie (Paris, 1899), esp. 12.

43. Georges Didi-Huberman, "La danse de toute chose," in Didi-Huberman and Mannoni, Mouvements de l'air: Etienne-Jules Marey, photographe des fluides, 173-337, here 213.

44. See François Albera, "Pour une epistemography du montage: le momentMarey," in Cinema Beyond Film: Media Epistemology in the Modern Era, ed. François Albera and Maria Tortajada (Amsterdam, 2010), 31-46; esp. 38.

45. See Etienne-Jules Marey to Samuel Langley, November 19, 1899, Smithsonian Institution Archives, Office of Secretary, 1887-1907, Record unit 31, book 26, folder 2.

46. Marey, "Des mouvements de l'air lorsqu'il rencontre des surfaces," 162.

47. Etienne-Jules Marey, Du mouvement dans les fonctions de la vie. Leçons faites au Collège de France (Paris, 1868), 93. See also Douard, "Etienne-Jules Marey's Visual Rhetoric," esp. 178-84.

48. Didi-Huberman names the recorded visual trace of the movement fittingly "time-trail"; in his opinion we can see the "wake of the temporalization" innate to the chronophotographs; see Didi-Huberman, "Der Strich, die Strähne," 295-96.

49. There exist only simple photographs of the smoke images, which, however, Marey does not call "snapshots" but "chronophotographs." For Laurent Mannoni this nomenclature has nonetheless some plausibility, because all three facets ("chrono," "photo," and "graphy") are present in these pictures: "chrono, thanks to the electric chronograph making the smoke nozzles undulate; photo of course, given that the process demands light (the flash) and the photographic apparatus; graphy because the bright traces left by the smoke tunnels on the sensitive plate are read and analyzed like a graph [ic]"; Mannoni, "Marey Aéronaute," 59.

50. See Marey, "Le mouvement des liquides." Etienne-Jules Marey, "The Experimental Study of the Motion of Fluids," Scientific American 86 (February 1, 1902): 75-76.

51. See F. A. Schraub et al., "Use of Hydrogen Bubbles for Quantitative Determination of Time-Dependent Velocity Fields in Low-Speed Water Flows," Journal of Basic Engineering 87, no. 2 (June 1, 1965): 429-44.

52. Henry V. Borst, The Aerodynamics of the Unconventional Air Vehicles of A. Lippisch (Wayne, PA, 1980), 1-14.

53. Michel Frizot, "Les opérateurs physiques de Marey et la réversibilité cinématographique," in Stop Motion: Fragmentation of Time, ed. François Albera, Marta Braun, and André Gaudreault (Lausanne, 2002), 91-102, here 97.

54. Henry Selby Hele-Shaw, "The Motion of a Perfect Liquid," Nature 60, no. 1558 (September 7, 1899): 446-51, here 446.

55. But Ahlborn conceives of the seeming disadvantages in a productive way. The fact that on the water's surface small islands of spores alternate with clear regions 
is advantageous for the photographic recording, so much so that Ahlborn himself boasts of it. If one blows the pellets about $30 \mathrm{~cm}$ above the water level into the air, they are distributed very homogenously. This helps the eye see the dynamic at every location. However, it is not suitable for photography that needs an optical difference. Thus Ahlborn disturbs the even distribution by agitating the water, potentially leading to the second problem: that the seeds adhere to each other. But even in this situation, the researcher succeeds, as he thereby learns why his rivals in Göttingen are misled in their theory about the process of detachment of the boundary layer. See Friedrich Ahlborn, Die photographische Strömungsanalyse: Versuchseinrichtungen und Verfahren, undated (after 1917), typescript, DMA/NL $091 \mathrm{~b}-88,1-7$, here 4 . A pragmatic approach with available means that allows him to recognize elements in their multiple functionality is typical for Ahlborn: "When I presented the first photograms of resistance flows at the Scientific Society in Hamburg [Naturwissenschaftlicher Verein zu Hamburg] in June 1900 , it was rightly asked whether the flow appearances on the surface corresponded to those in the inner liquid and whether the former would or would not be significantly influenced by the surface tension. The answer is that the tension on the surface of the water is eliminated by the scattered club moss spores as by every other dust particle"; Ahlborn, Über den Mechanismus des hydrodynamischen Widerstandes, 29.

56. Nonetheless, sometimes ambiguities arise that have to do with the specific visualization: "In reality many lines turn out to be longer as these optical traces easily overlap if the clusters of the club moss meal are positioned close in front of each other. Furthermore, as the chemical process of the flash explosion fades gradually, so the lines also begin to develop by degrees on the dark background. With the greatest light intensity they reach their greatest sharpness, and on the other end they again trail off in the darkness as they emerged from it. Their ends appear most defined in strongly enhanced transparencies and their projection images"; ibid., 11.

57. Ibid., 10.

58. Friedrich Ahlborn, "Die Widerstandsvorgänge im Wasser an Platten und Schiffskörpern: Die Entstehung von Wellen," Jahrbuch der Schiffsbautechnischen Gesellschaft (1909): 370-436, here 373.

59. Ahlborn, Die photographische Strömungsanalyse.

60. In recordings with a long exposure time, the dot-like depictions materialize only because the relevant area remains in an invariant position with respect to the camera.

61. Friedrich Ahlborn, "Hydrodynamische Experimentaluntersuchungen," Jahrbuch der Schiffsbautechnischen Gesellschaft (1904): 417-53, here 423-25.

62. Friedrich Ahlborn, Hydrodynamische Kraftfelder, undated, typescript, DMA/NL $091 \mathrm{k}-84,1$.

63. Ahlborn, "Turbulenz und Mechanismus des Widerstandes," 482.

64. Ahlborn, Über den Mechanismus des hydrodynamischen Widerstandes, 26.

65. Ahlborn, "Die Widerstandsvorgänge im Wasser," 411-13.

66. It remains unclear why Ahlborn most often transcribes only flow and force lines into his drawings, but hardly ever path lines. As Ahlborn's photographs aim at recording striated-blurred as well as dotted zones at the same time, it is striking to see that in his drawings he most often depicts the situation with lines-regardless of this given differentiation. Graphically, Ahlborn does not make a distinction between "moved" and "still." The difference lies merely in the fact that areas that appear as points are not rendered as tubelike longish formations. 
67. The clear contouring of the vortex pair represents a clarification that in nature is nonexistant in the shown form. On another occasion (for the threedimensional representation), Ahlborn states: "Needless to say that the ... sharp contours chosen for the schematic depiction of these forms do not exist in reality because the circular movement of a vortex gradually fades and dies off toward the edge and theoretically ceases only in infinity"; Friedrich Ahlborn, "Turbulenz und Geschwindigkeitsverteilung in Flussläufen," Physikalische Zeitschrift 23, no. 3 (February 1, 1922): 57-65, here 59-60.

68. Sometimes in his descriptions, different logics of zoning are revealed. Even if Ahlborn subdivides the whole scene with his drawn flow lines into water threads, this does not stop him from speaking of the "two" lateral flows (these are units encompassing several water threads that do not directly take part in the eddies). See Ahlborn, "Die Widerstandsvorgänge im Wasser," 395-96.

69. Ahlborn, "Hydrodynamische Experimentaluntersuchungen," 423. See also Ahlborn, "Die Widerstandserscheinungen in flüssigen Medien," 189-90. Daniel Bernoulli, Hydrodynamica (Strasbourg, 1738), esp. chap. 4, §3 and $\$ 15$.

70. Ahlborn, "Hydrodynamische Experimentaluntersuchungen," 425.

71. Ahlborn, "Über den Mechanismus des Widerstandes," 121.

72. See Friedrich Ahlborn, "Der Magnuseffekt in Theorie und Wirklichkeit," Zeitschrift für Flugtechnik und Motor-Luftschifffahrt 20 (1929): 642-53, here 647; Friedrich Ahlborn, "Über theoretische und natürliche Strömungen," Flugwesen 10, no. 1 (1930): 1-6, here 1-2.

73. David Gooding, "Magnetic Curves' and the Magnetic Field: Experimentation and Representation in the History of a Theory," in The Uses of Experiment: Studies in the Natural Sciences, ed. David Gooding, Trevor Pinch, and Simon Schaffer (Cambridge, MA, 1989), 183-223, here 209. See also Peter Barlow, An Essay on Magnetic Attractions (London, 1823).

74. Gooding, "'Magnetic Curves," 214-15. See also Michael Faraday, "Magnetic Conducting Power," in Experimental Researches in Electricity (London, 1855), 3: 200-73, here 203, § 2804.

75. Jean-Luc Daval, La Photographie: Histoire d'un Art (Lausanne, 1982), 72.

76. Bernd Stiegler, Theoriegeschichte der Photographie (Munich, 2006), 97-99. For the quotation within the quotation, see Pontus Hultén, "Etienne-Jules Marey et la mise à nu de l'espace/temps," in E.J. Marey, 1830/1904: La Photographie du Mouvement (Paris, 1977), 7-8, here 7.

77. See Lorraine Daston and Peter Galison, Objectivity (New York, 2007).

78. See Etienne-Jules Marey, "Nécessité de créer une commission internationale pour l'unification et le contrôle des instruments inscripteurs physiologiques," Journal of Physiology 23, supplement (1898-1899): 6-7. The idea of "autographic depictions" is expressed in Friedrich Ahlborn, "Analyse des Widerstandes durch Stauversuche," in Über den Mechanismus des hydrodynamischen Widerstandes, 42. See also Friedrich Weltzien, ed., Von selbst. Autopoietische Verfahren in der Ästhetik des 19. Jahrhunderts (Berlin, 2006).

79. Thirty years after these experiments, the surrealist artist Max Ernst addressed the pictorial language of the physicists in his series Blind Swimmers of 1934. According to the analyses presented here regarding the use of parallelaligned lines, one can draw the conclusion that Ernst not only translated Marey's 1901 aerodynamic studies (as in the version of that painting called Blind Swimmers [Effect of a Touch], 1934, Julien Levy Collection, Bridgewater [CT]; see 
Braun, Picturing Time, 314-16) but also appropriated the logic of lines diametrically opposed to Marey's (thus oriented toward Faraday's logic; see the painting The Blind Swimmer, 1934, Museum of Modern Art, New York). This confirms the findings of Charlotte Stokes, who identified Ernst's direct sources of inspiration in the scientific journal La nature: revue des sciences et de leurs applications aux arts et à l'industrie 17, no. 2 (1901). See Charlotte Stokes, "The Scientific Methods of Max Ernst: His Use of Scientific Subjects from La Nature," Art Bulletin 62, no. 3 (September 1980): 453-65, here 462-463. However, Stokes does not give an account of the authors of the adopted images and articles. In order to take up the slack, the artist used images from the following articles: Marey, "Les mouvements de l'air étudiés par la chronophotographie," fig. 5; Lucien Bull, "La photographie des mouvements invisibles: Expériences de M. Hele-Shaw," 247-50, from which Ernst used figs. 3 and 6 or 7. The last two depictions indeed represent magnetic force lines, according to Bull, Marey's assistant from 1895-1904.

80. W. J. T. Mitchell, "Showing Seeing: A Critique of Visual Culture," Journal of Visual Culture 1, no. 2 (2002): 165-81, here 170-71. 